\title{
Evolution, dynamics, and fixed points
}

Citation for published version (APA):

Joosten, R. A. M. G. (1995). Evolution, dynamics, and fixed points. MERIT, Maastricht Economic Research Institute on Innovation and Technology. MERIT Research Memoranda No. 005 https://doi.org/10.26481/umamer.1995005

Document status and date:

Published: 01/01/1995

DOI:

10.26481/umamer.1995005

Document Version:

Publisher's PDF, also known as Version of record

\section{Please check the document version of this publication:}

- A submitted manuscript is the version of the article upon submission and before peer-review. There can be important differences between the submitted version and the official published version of record.

People interested in the research are advised to contact the author for the final version of the publication, or visit the DOI to the publisher's website.

- The final author version and the galley proof are versions of the publication after peer review.

- The final published version features the final layout of the paper including the volume, issue and page numbers.

Link to publication

\footnotetext{
General rights rights.

- You may freely distribute the URL identifying the publication in the public portal. please follow below link for the End User Agreement:

www.umlib.nl/taverne-license

Take down policy

If you believe that this document breaches copyright please contact us at:

repository@maastrichtuniversity.nl

providing details and we will investigate your claim.
}

Copyright and moral rights for the publications made accessible in the public portal are retained by the authors and/or other copyright owners and it is a condition of accessing publications that users recognise and abide by the legal requirements associated with these

- Users may download and print one copy of any publication from the public portal for the purpose of private study or research.

- You may not further distribute the material or use it for any profit-making activity or commercial gain

If the publication is distributed under the terms of Article $25 \mathrm{fa}$ of the Dutch Copyright Act, indicated by the "Taverne" license above, 


\title{
EVOLUTION, DYNAMICS, AND \\ FIXED POINTS ${ }^{\mathrm{a}}$
}

\author{
by \\ Reinoud JOOSTEN ${ }^{\mathrm{b}}$ \\ February 1995
}

\begin{abstract}
Sign-compatible dynamics describe changes in the composition of a population driven by differences in fitness. A saturated equilibrium is a fixed point for sign-compatible dynamics where each subgroup with positive population share has highest fitness. An evolutionary stable equilibrium is a saturated equilibrium attracting all trajectories nearby, such that the Euclidean distance to it decreases monotonically. We address existence, multiplicity, and dynamical stability of fixed points of sign-compatible dynamics. A saturated equilibrium may be approximated by using a variable dimension restart algorithm for solving the nonlinear complementarity problem.
\end{abstract}

Journal of Economic Literature Classification Numbers: C62, C68, C72, C73.

Keywords: Sign-compatible population dynamics, saturated equilibrium, evolutionary stable equilibrium, dynamic stability, nonlinear complementarity problem.

\footnotetext{
${ }^{a}$ I thank Bart Verspagen, Hans Peters, Frank Thuijsman, Dolf Talman, Eric van Damme, Antoon van den Elzen, Richard Nelson, Hans van der Stel, Theon van Dijk and an anonymous referee for comments and/or encouragement on earlier versions of this paper. Participants at the 1993 EARIE-conference in Tel Aviv, and in a game theory seminar organized by Center|Tilburg University are thanked for suggestions. Mistakes are mine.

${ }^{\mathrm{b}}$ Maastricht Economic Research Institute on Innovation and Technology, and Department of Mathematics, University of Limburg, P.O. Box 616, 6200 MD Maastricht, The Netherlands.
} 


\section{Introduction}

The main equilibrium concepts in evolutionary game theory are the Nash equilibrium (Nash, 1951) and the evolutionary stable strategy (Maynard Smith and Price, 1973). Taylor and Jonker (1978) introduced the replicator dynamics into game theory. They showed that for a large class of normal form games, each Nash equilibrium corresponds with a fixed point of these dynamics, and furthermore that each evolutionary stable strategy corresponds with an asymptotically stable fixed point. The latter implies that the dynamical system converges to such an evolutionary stable strategy from all states which are sufficiently nearby. For long, the replicator dynamics have virtually monopolized evolutionary modelling in game theory. Only recently, interest in larger classes of dynamics plausible in an evolutionary modelling framework, has risen. Nachbar (1990) showed for a class of normal form games that if evolutionary dynamics converge from the interior of the state space to a point, then it corresponds with a Nash equilibrium. Thus, a surprising motivation of the standard solution concept in game theory was provided: a Nash equilibrium may develop as a product of selective pressures, even in (total) absence of rationality on the level of the individual agents.

Similar dynamical processes may be, and in fact are, employed in economics and other social sciences, where an interpretation of rationality as a result of 'evolutionary' selection has considerable appeal. Evolutionary dynamics are also used as a metaphor for various learning processes (e.g., Zeeman, 1981, Friedman, 1991, Mailath, 1992). Alchian (1950), and Friedman (1953) use the argument of natural selection informally for the defense of the hypothesis of profit maximization. Nelson and Winter (1982) incorporate 'evolutionary' selection arguments in a formal approach to economic change. Further contributions in economics featuring 'evolutionary' dynamics include e.g., Winter (1964, 1971), Dow (1986), Dosi et al. (1988), Nachbar (1991) on Hansen and Samuelson (1988), or Metcalfe (1994). Hannan and Freeman (1989) employ selection dynamics for populations of organizations exhibiting structural strategic inertia. Finally, Axelrod and Hamilton (1981), and Axelrod (1984) have become the standard allegories for the evolution to cooperation in societies consisting of selfish agents. In mathematical biology, the (bi)linearity of fitness functions as yielded by normal form games is sometimes abandoned (cf. Hofbauer and Sigmund, 1988), as this feature is unduely restrictive for instance for settings with positive or negative 
frequency-dependent feedbacks, with asymmetric contests, or with viscous populations (Myerson et al, 1991). Furthermore, outside the context of mathematical biology, the replicator dynamics are far less compelling as 'evolutionary' dynamics.

We therefore study a large class of deterministic population dynamics, meanwhile allowing very general fitness functions. We strip off as many details as possible from the various evolutionary approaches. Hence, we are left with the bare essentials of 'evolutionary' modelling, creating the generality necessary to follow a uniform approach in separate fields. All strategical interactions and other relevant influences, are assumed to be captured by a continuous fitness function, which depends on the composition of the population. From this function, the relative fitness function is derived, which attributes for every state to each subgroup in the population the difference between the subgroup's fitness and the population share weighted average fitness of the population. A relative fitness function satisfies continuity and complementarity, and in deriving the majority of our results, we use no additional requirements. Our population dynamics are sign-compatible with the relative fitness function, which implies that the change in population share of any subgroup with positive population share, corresponds in sign with the relative fitness of this subgroup.

We focus on fixed point concepts of sign-compatible dynamics, most of which may be found in standard textbooks on dynamical systems (e.g., Hirsch and Smale, 1974). Two concepts which we regard as particularly relevant for evolutionary modelling, are the saturated equilibrium (Hofbauer and Sigmund, 1988) and the evolutionary stable equilibrium. A saturated equilibrium implies 'extinction of the less fit', since each subgroup with belowmaximum fitness has population share equal to zero at such a state. Furthermore, each subgroup with positive population share has highest fitness. We prove that existence of at least one saturated equilibrium for arbitrary relative fitness functions is guaranteed, and each saturated equilibrium is a fixed point for all sign-compatible dynamics. Furthermore, if any trajectory under these dynamics converges from the interior of the state space, then its limit point is a saturated equilibrium. For most practical purposes only the stable fixed points of a dynamical system are relevant. We show that any stable fixed point of sign-compatible dynamics is a saturated equilibrium. The evolutionary stable equilibrium is defined in terms of local properties of the dynamical system. We prove that any trajectory reaching a certain neighborhood of an evolutionary stable equilibrium, converges monotonically towards it, which means that the Euclidean distance to this fixed point decreases strictly in time. For 
normal form games, we derive conditions where our notion of evolutionary stability implies strategic stability, and conversely. Finally, we show that each saturated equilibrium can be associated with a symmetric Nash equilibrium of a 'derived' bi-matrix game, and vice versa.

We address the topics of multiplicity, stability and computability of fixed points of sign-compatible dynamics. An interesting by-product of our analysis is that we were able to show and consequently mathematical similarities between relative fitness functions and generalized excess demand functions for pure exchange economies with normalized prices. We derive conditions for uniqueness of an interior saturated equilibrium, which imply either asymptotical stability, or dynamic instability of this fixed point. We remark that finding arbitrary fixed points is a trivial problem, since each vertex of the state space is a fixed point. However, a vertex need not be saturated, in which case it is dynamically unstable for all sign-compatible dynamics. As the dynamical system is generally nonlinear, it may display a high degree of complexity. Hence, researchers interested in finding saturated equilibria or stable fixed points of sign-compatible dynamics, may encounter computational problems. A variable dimension restart algorithm to solve the nonlinear complementarity problem, may be used to find a saturated equilibrium. Such an algorithm may be started in an arbitrary point of the state space, and it converges to an arbitrarily accurate approximation of a saturated equilibrium for arbitrary relative fitness functions. Research indicates that the algorithm of Doup et al. (1987) is very efficient.

The generality of our model allows applications in mathematical biology, economics, and other social sciences. Throughout this paper we will use a terminology from evolutionary game theory or mathematical biology. However, in the various contexts states may have different interpretations, e.g., strategies, population shares, market shares, whereas the 'subgroups' may be players, agents, firms, organizations, etc. Fitness may require translation too, e.g., payoffs, revenue, profits, potential to grow. The dynamical process can be selection dynamics, market dynamics, or a learning process.

We formulate the model in the next section. We compare the saturated equilibrium and the evolutionary stable equilibrium with standard fixed-point-concepts, and with equilibrium concepts from game theory. In Section 3, we derive conditions for stability and uniqueness of fixed points. In Section 4, we give a procedure to find fixed points, which includes a variable dimension restart algorithm for solving the nonlinear complementarity problem, to approximate a saturated equilibrium. Section 5 concludes. 


\section{The evolutionary model}

We consider a population which consists of $n+1$ distinguishable, (strategically) interacting subgroups. The population as well as the subgroups are assumed to be very large, or alternatively the number of interactions is very large. The interaction of the subgroups has consequences on their respective abilities to reproduce, and 'fitness' may be seen as a measure of ability to reproduce. The fitness of a subgroup is determined by its genetically given behavior in combination with the composition of the population. Since behavior is assumed to be predetermined, fitness can be treated as depending solely on the composition of the population. Let $\mathrm{p}$ be a nonnegative integer, let $\mathrm{I}^{\mathrm{p}+1}=\{1, \ldots, \mathrm{p}+1\}$, let $\mathrm{x}=\left(\mathrm{x}_{1}, \ldots, \mathrm{x}_{\mathrm{n}+1}\right)^{\mathrm{T}} \in$ $S^{n}=\left\{y \in \mathbb{R}^{n+1} \mid \sum_{j} y_{j}=1, y_{i} \geq 0\right.$ for all $\left.\mathrm{i} \in I^{n+1}\right\}$, denote a vector of population shares, henceforth to be called a state. The population share of subgroup $i \in I^{n+1}$ at state $x$ is therefore $\mathrm{x}_{\mathrm{i}}$. Let $\mathrm{E}: \mathrm{S}^{\mathrm{n}} \rightarrow \mathbb{R}^{\mathrm{n}+1}$ be a continuous (multi)function, attributing to every subgroup its fitness at each state. We will refer to the function $\mathrm{E}$ as the fitness function. All stategical interaction, as well as all possible other influences on the fitnesses of the subgroups, are assumed to be fully captured by this function.

Time-notations are suppressed whenever confusion is unlikely. Let $\mathrm{p}$ be a positive integer, $x, y \in \mathbb{R}^{n+1}$, then the $\underline{\mathrm{p} \text {-norm }}$ is $\|\mathrm{x}\|_{\mathrm{p}}=\left(\sum_{\mathrm{i}}\left|\mathrm{x}_{\mathrm{i}}\right|^{\mathrm{p}}\right)^{1 / \mathrm{p}}$, the length of $\mathrm{x}$ is $\|\mathrm{x}\|_{2}$, the $\underline{\text { inner }}$ product is $\mathrm{x}^{\mathrm{T}} \mathrm{y}=\Sigma_{\mathrm{i}} \mathrm{x}_{\mathrm{i}} \mathrm{y}_{\mathrm{i}}$, and the Euclidean distance between $\mathrm{x}$ and $\mathrm{y}$ is $\mathrm{d}_{2}(\mathrm{x}, \mathrm{y})=\|\mathrm{x}-\mathrm{y}\|_{2}$. Furthermore, $e_{j}, j \in I^{n+1}$, is the vertex $x \in S^{n}$ with $x_{j}=1$. For $z \in \mathbb{R}^{n+1}$, we write for example, $\mathrm{z} \geq \mathbf{0}$, meaning $\mathrm{z}_{\mathrm{i}} \geq 0$ for all $\mathrm{i} \in \mathrm{I}^{\mathrm{n}+1}$. The convex hull of $\left\{\mathrm{x}^{1}, \ldots, \mathrm{x}^{\mathrm{k}}\right\} \subset \mathbb{R}^{\mathrm{n}+1}$, is $\operatorname{conv}\left\{\mathrm{x}^{\mathrm{j}} \mid \mathrm{j} \in\right.$ $\left.\mathrm{I}^{\mathrm{k}}\right\}=\left\{\mathrm{y} \in \mathbb{R}^{\mathrm{n}+1} \mid \mathrm{y}=\sum_{\mathrm{j}} \lambda_{\mathrm{j}} \mathrm{x}^{\mathrm{j}}\right.$, where $\sum_{\mathrm{j}} \lambda_{\mathrm{j}}=1$, and $\lambda_{\mathrm{j}} \geq 0$ for all $\left.\mathrm{j} \in \mathrm{I}^{\mathrm{k}}\right\}$. The boundary of $\mathrm{S}^{\mathrm{n}}$, bd $S^{n}$, is defined by bd $S^{n}=\left\{x \in S^{n} \mid x_{i}=0\right.$ for some $\left.i \in I^{n+1}\right\}$. The interior of $S^{n}$, int $S^{n}$, is defined by int $S^{n}=S^{n} \backslash\left(\right.$ bd $\left.S^{n}\right)$. We denote the cardinality of a set $S$ by $|S|$. Let $K \subset I^{n+1}$, then the set $S^{n}(K)$, defined by $S^{n}(K)=\left\{x \in S^{n} \mid x_{j}=0\right.$ if $\left.j \in K\right\}$, is called a $\underline{k \text {-face of }} S^{n}$, where $k=\left|I^{n+1}\right| K \mid$. A k-face $S^{n}(K)$ is called a facet of $S^{n}$ if $k=n$.

The relative fitness function $\mathrm{f}: \mathrm{S}^{\mathrm{n}} \rightarrow \mathbb{R}^{\mathrm{n}+1}$ is given by

$$
f_{i}(x)=E_{i}(x)-\sum_{j} x_{j} E_{j}(x) \quad \text { for all } i \in I^{n+1}, x \in S^{n} .
$$

A (multi)function, say $\mathrm{h}: \mathrm{Z} \rightarrow \mathrm{D}$ with $\mathrm{Z}, \mathrm{D}$ subsets of the same finite-dimensional Euclidean 
space, satisfies complementarity if $\mathrm{x}^{\mathrm{T}} \mathrm{h}(\mathrm{x})=0$ for all $\mathrm{x} \in \mathrm{Z}$. From Eq. (1) it may be derived that every relative fitness function satisfies complementarity. Unless specificly mentioned otherwise, we treat relative fitness functions as if characterized by continuity and complementarity.

To model the evolution of the composition of the population, we consider a dynamic process represented by the following system of $n+1$ autonomous differential equations:

$$
\mathrm{dx} / \mathrm{dt}=\mathrm{G}(\mathrm{x}) \quad \text { for all } \mathrm{x} \in \mathrm{S}^{\mathrm{n}}
$$

where $d x / d t=\left(d_{1} / d t, \ldots, d x_{n+1} / d t\right)^{T}=\left(G_{1}(x), \ldots, G_{n+1}(x)\right)^{T}$, denotes the continuous-time changes of the population shares of all subgroups. We require that the function $\mathrm{G}$ fulfills the following criterium, namely sign-compatibility. Let $\mathrm{f}: \mathrm{S}^{\mathrm{n}} \rightarrow \mathbb{R}^{\mathrm{n}+1}$ be a relative fitness function, then the function $G: S^{n} \rightarrow \mathbb{R}^{n+1}$, is $\underline{\text { sign-compatible }}^{1}$ if
(a) $\mathrm{G}$ is (Lipschitz) continuous,
(b) $\quad \Sigma_{\mathrm{i}} \mathrm{G}_{\mathrm{i}}(\mathrm{x})=0$ for all $\mathrm{x} \in \mathrm{S}^{\mathrm{n}}$,
(c) $\quad \mathrm{x}_{\mathrm{i}}=0$ implies $\mathrm{G}_{\mathrm{i}}(\mathrm{x})=0$ for all $\mathrm{x} \in \mathrm{S}^{\mathrm{n}}, \mathrm{i} \in \mathrm{I}^{\mathrm{n}+1}$, and
(d) $\quad \mathrm{x}_{\mathrm{i}}>0$ implies $\operatorname{sign} \mathrm{G}_{\mathrm{i}}(\mathrm{x})=\operatorname{sign} \mathrm{f}_{\mathrm{i}}(\mathrm{x})$ for all $\mathrm{x} \in \mathrm{S}^{\mathrm{n}}, \mathrm{i} \in \mathrm{I}^{\mathrm{n}+1}$.

For $\mathrm{y} \in \mathbb{R}$, $\underline{\text { sign } \mathrm{y}}$ is defined as: sign $\mathrm{y}=+1$ if $\mathrm{y}>0$, sign $\mathrm{y}=0$ if $\mathrm{y}=0$, and sign $\mathrm{y}=-1$ if $\mathrm{y}<0$. Population dynamics are sign-compatible if the function $\mathrm{G}$ in (2) is sign-compatible. Note that the replicator dynamics are sign-compatible. Sign-compatibility is considerably weaker than Friedman's (1991) order compatibility combined with admissibility, but somewhat stronger than weak compatibility combined with admissibility.

A trajectory under $\mathrm{G}$, denoted by $\{\mathrm{x}(\mathrm{t})\}_{\mathrm{t} \geq 0}$, is a sequence of points being a solution to $\mathrm{x}(0)=\mathrm{x}_{0}$ for some $\mathrm{x}_{0} \in \mathrm{S}^{\mathrm{n}}$, and for all $\mathrm{t}^{\prime} \geq 0: \mathrm{dx}(\tau) / \mathrm{d} \tau=\mathrm{G}(\mathrm{x}(\tau))$ for all $\tau \in\left[0, \mathrm{t}^{\prime}\right]$. For signcompatible population dynamics, the change in population share of each nonextinct subgroup corresponds in sign with its relative fitness. Property (a) can be used in the strong version, i.e., Lipschitz continuity, or the weaker one. Existence of a solution is guaranteed by continuity, whereas Lipschitz continuity additionally guarantees uniqueness. An even stronger

\footnotetext{
${ }^{1}$ An anonymous referee suggested this nomenclature.
} 
property, which implies Lipschitz continuity for a compact state space, is that the function $\mathrm{G}$ has continuous partial derivatives at each state. Property (c) may be viewed as strong, but as we usually assume that all subgroups are present in the population, the implications of this requirement will in effect not be unduely restrictive.

The state $y \in S^{n}$ is a fixed point if $G(y)=\mathbf{0}$ in Equation (2). At a fixed point changes in the composition of the population come to a rest. The state $y \in \mathbb{R}^{\mathrm{n}+1}$, is a limit point if there exists at least one trajectory $\{\mathrm{x}(\mathrm{t})\}_{\mathrm{t} \geq 0} \subset \mathrm{S}^{\mathrm{n}}$, such that $\mathrm{G}(\mathrm{x}(0)) \neq \mathbf{0}$ and $\operatorname{Lim}_{\mathrm{t} \rightarrow \infty} \mathrm{x}(\mathrm{t})=\mathrm{y}$. Continuity of sign-compatible dynamics and the compactness of $S^{n}$, imply that $G(y)=\mathbf{0}$ and $\mathrm{y} \in \mathrm{S}^{\mathrm{n}}$. The fixed point $\mathrm{y} \in \mathrm{S}^{\mathrm{n}}$ is $\underline{\text { stable }}$ if for any open neighborhood $\mathrm{U} \subset \mathrm{S}^{\mathrm{n}}$ of $\mathrm{y}$, an open neighborhood $\mathrm{V}$ of $\mathrm{y}$ exists such that any trajectory starting in $\mathrm{V}$ remains in $\mathrm{U}$. A fixed point is unstable if it is not stable. The stable fixed point $y \in S^{n}$ is asymptotically stable if $y$ is a limit point of all trajectories starting in $\mathrm{V} \backslash\{\mathrm{y}\}$. Hirsch and Smale (1974) treat several methods to examine the dynamical stability of fixed points. We use Lyapunov's second method on several occasions, which can be extended to examine sets of fixed points.

The state $\mathrm{y} \in \mathrm{S}^{\mathrm{n}}$ is a saturated equilibrium if $\mathrm{f}(\mathrm{y}) \leq \mathbf{0}$ (Hofbauer and Sigmund, 1988). A saturated equilibrium $y$ is $\underline{\text { strict }}$ if $\mathrm{f}_{\mathrm{j}}(\mathrm{y})=0$ for precisely one $\mathrm{j} \in \mathrm{I}^{\mathrm{n}+1}$. At a saturated equilibrium each group with positive population share has highest fitness. Any group with below-average-fitness has population share equal to zero. The following four propositions and two corollaries pertain to arbitrary relative fitness functions and arbitrary sign-compatible dynamics. All proofs may be found in the Appendix.

Proposition 2.1. There exists at least one saturated equilibrium.

Proposition 2.2. Every saturated equilibrium is a fixed point.

Each unstable interior fixed point is a saturated equilibrium, hence not every saturated equilibrium is stable. The following shows further connections.

Proposition 2.3. Every strict saturated equilibrium is a vertex, moreover it is an asymptotically stable fixed point.

Proposition 2.4. Every stable fixed point is a saturated equilibrium. 
The latter proposition implies that any fixed point that is not a saturated equilibrium is dynamically unstable. Furthermore, the proof of Proposition 2.4 leads to the following.

Corollary 2.1. No fixed point in bd $S^{n}$ that is not a saturated equilibrium, is reached by any trajectory for sign-compatible dynamics from the relative interior of $S^{n}$.

Suppose $\mathrm{y} \in \mathrm{S}^{\mathrm{n}}$ is a limit point for some trajectory $\{\mathrm{x}(\mathrm{t})\}_{\mathrm{t} \geq 0}$, with $\mathrm{x}(0)=\mathrm{x}_{0} \in$ int $\mathrm{S}^{\mathrm{n}}$. Then obviously either $\mathrm{y} \in \operatorname{int} \mathrm{S}^{\mathrm{n}}$, or $\mathrm{y} \in \mathrm{bd} \mathrm{S}^{\mathrm{n}}$. Corollary 2.1 applies to the latter case, and all interior fixed points of sign-compatible dynamics are saturated equilibria. Finally, a trajectory starting in an interior fixed point, never leaves this state. This proves the ensuing corollary.

Corollary 2.2. Any trajectory under sign-compatible dynamics starting in the relative interior of the state space, converges only to a saturated equilibrium.

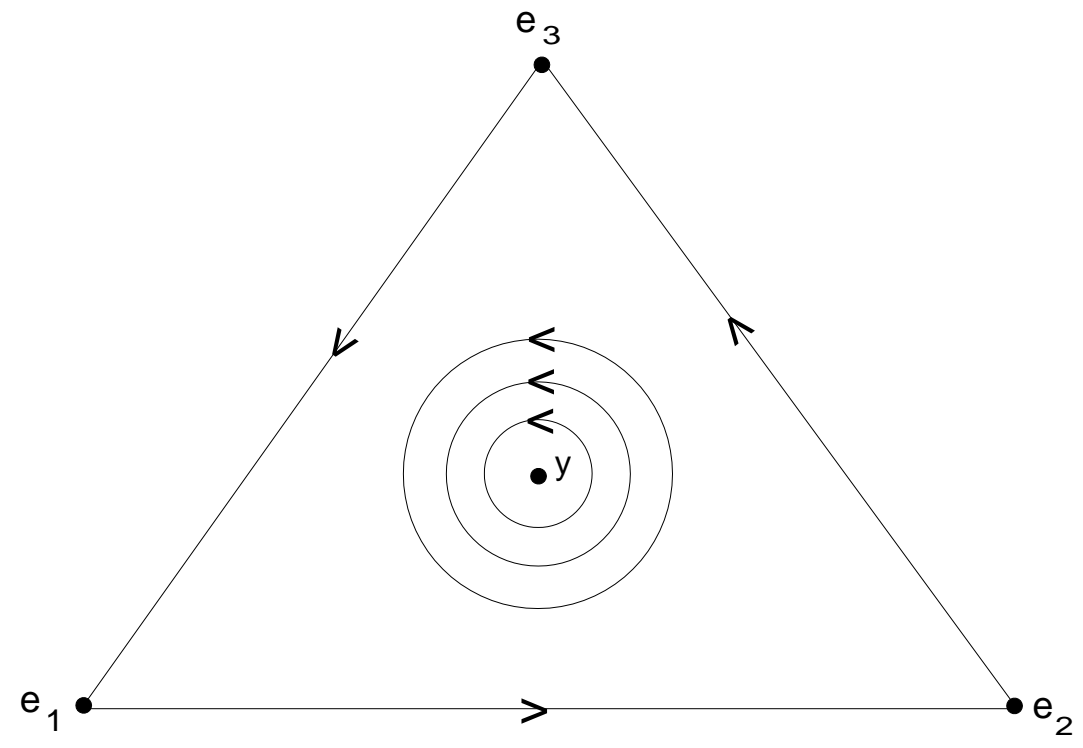

Figure 1. The saturated equilibrium y is stable, it is not a limit point; vertices $e_{1}, e_{2}, e_{3}$ are unstable limit points.

We will expand on the connections and discrepancies of this corollary and a result in Nachbar (1990) in Propositions 2.6 and 2.7. A limit point need not be a stable fixed point, nor need it be that a stable fixed point is a limit point in general, see e.g. Figure 1. Figure 1 also illustrates that not every trajectory has a limit point.

The fixed point $y \in S^{n}$, is an evolutionary stable equilibrium if and only if there exists 
an open neighborhood $U \subset S^{n}$ of y satisfying

$$
\mathrm{y}^{\mathrm{T}} \mathrm{G}(\mathrm{x})>\mathrm{x}^{\mathrm{T}} \mathrm{G}(\mathrm{x}) \quad \text { for all } \mathrm{x} \in \mathrm{U} \backslash\{\mathrm{y}\}
$$

Let a relative fitness function be arbitrary, let sign-compatible dynamics be given, and let ESE, ASFP, SSAT denote the sets of all evolutionary stable equilibria, asymptotically stable fixed points, and strict saturated equilibria respectively. Then the connections between these sets are the following.

Proposition 2.5. $S S A T \subseteq E S E \subseteq A S F P$.

An evolutionary stable equilibrium need not be a vertex of $\mathrm{S}^{\mathrm{n}}$, hence SSAT $\neq$ ESE in general. By definition each asymptotically stable fixed point is stable, as well as a limit point. In part (a) of the proof of Proposition 2.5, we use the strict Lyapunov function V, which is defined by $\mathrm{V}(\mathrm{x})=-1 / 2\left(\mathrm{~d}_{2}(\mathrm{x}, \mathrm{y})\right)^{2}$ where $\mathrm{y}$ is the evolutionary stable equilibrium. Hence, the following.

Corollary 2.3. The Euclidean distance to an evolutionary stable equilibrium decreases monotonically in time along any trajectory starting sufficiently close to it.

The property of the dynamics formulated in Eq. (3), leading to Corollary 2.3, is sufficient for asymptotical stability, but it is not a necessary condition. It may happen that a trajectory which starts near an asymptotically stable fixed point, moves quite far away from the fixed point before converging. Hence, evolutionary stability is a more stringent requirement than asymptotical stability, and therefore ESE $\neq$ ASFP. Weissing (1990) makes a similar distinction with respect to asymptotical and evolutionary stability in evolutionary games. An alternative (geometrical) interpretation of Eq. (3) is that the angle between the vectors $(y-x)$ and $\mathrm{G}(\mathrm{x})$ is always sharp in $\mathrm{U} \backslash\{\mathrm{y}\}$. For normal form games, evolutionary stability of an interior Nash equilibrium additionally implies asymptotical stability for the entire interior of the state space under the replicator dynamics. The latter aspect may carry over to models with bilinear relative fitness functions. It need however not carry over to a model with an arbitrary relative fitness function, and hence there may exist several interior evolutionary stable equilibria. 
In contrast to the saturated equilibrium, none of its 'refinements' need to exist in general. Figure 1 illustrates the case where neither a limit point for any trajectory in the interior of the unit simplex, nor an asymptotically stable fixed point exist. Hence, by Proposition 2.5 neither evolutionary stable equilibria, nor strict saturated equilibria exist. Figure 2 illustrates the case where no limit point for any interior trajectory, and therefore no asymptotically stable fixed point, exists.

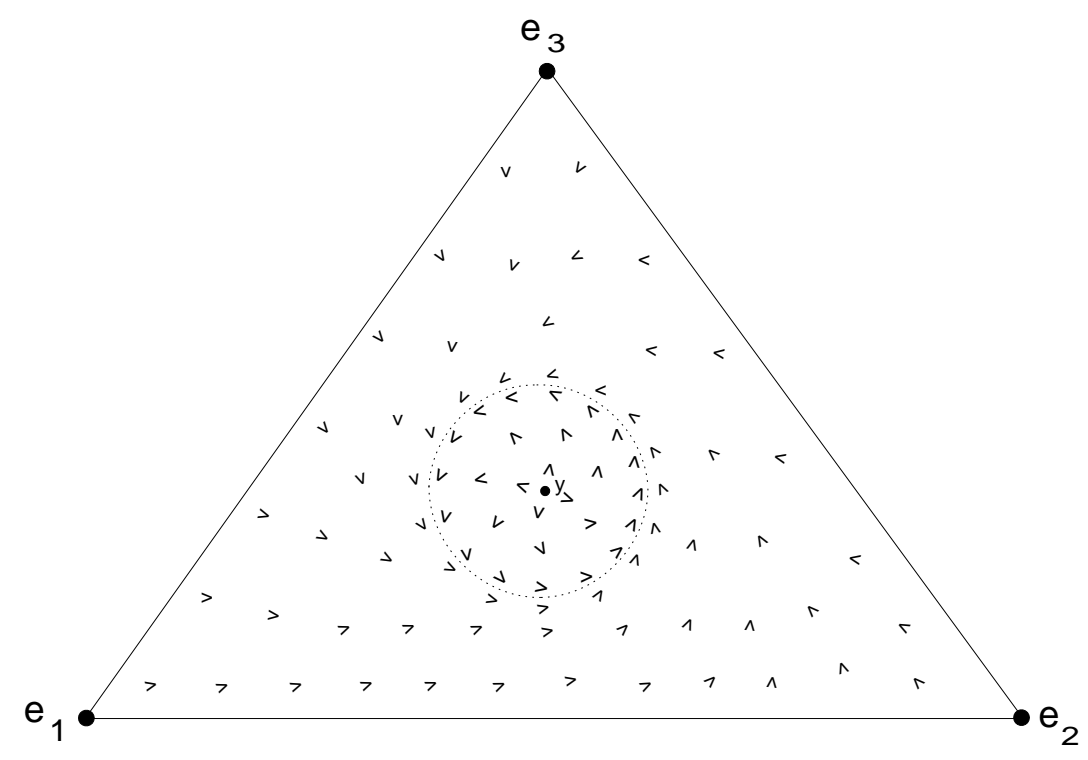

Figure 2. Adapted from Varian (1978), Scarf (1960). Arrowheads indicate directions of the dynamics. All interior trajectories converge to the dotted cycle. The saturated equilibrium y is unstable.

We turn briefly to normal form evolutionary games. Assume that the relative fitness function is given by (Bomze and Van Damme, 1992)

$$
f_{k}(x)=\left(s^{k}\right)^{T} A\left(\sum_{j} x_{j} j^{j}\right)-\left(\sum_{j} x_{j} j^{j}\right)^{T} A\left(\sum_{j} x_{j} s^{j}\right) \text { for all } x \in S^{n}, k \in I^{n+1}
$$

where $A$ is an $(m+1) \times(m+1)$-matrix, and $s^{k} \in S^{m}$ is the fixed inheritable strategy of subgroup $\mathrm{k} \in \mathrm{I}^{\mathrm{n}+1}$. The population strategy is the population share weighted average strategy, $\sum_{\mathrm{j}} \mathrm{x}_{\mathrm{j}} \mathrm{s}^{\mathrm{j}}$. Under the standard assumption that each individual is matched with another individual with a probability that is exactly equal to the population share of the subgroup to which the latter individual belongs, it is as if the former individual plays against the population strategy. This results in a fitness of subgroup $k \in \mathrm{I}^{\mathrm{n}+1}$ of $\left(\mathrm{s}^{\mathrm{k}}\right)^{\mathrm{T}} \mathrm{A}\left(\sum_{\mathrm{j}} \mathrm{x}_{\mathrm{j}} \mathrm{s}^{\mathrm{j}}\right)$, hence the population share 
weighted average fitness of the population is equal to $\sum_{j} x_{j}\left(\left(s^{j}\right)^{T} A\left(\sum_{j} x_{j} s^{j}\right)\right)=\left(\sum_{j} x_{j} s^{j}\right)^{T} A\left(\sum_{j}\right.$ $\mathrm{x}_{\mathrm{j}} \mathrm{s}^{\mathrm{j}}$ ) for all $\mathrm{x} \in \mathrm{S}^{\mathrm{n}}, \mathrm{k} \in \mathrm{I}^{\mathrm{n}+1}$. This motivates (4).

For the symmetric bimatrix game $\left(B, B^{T}\right)$, where $B$ is an $(n+1) \times(n+1)$-matrix, the mixed strategy combination $(\mathrm{y}, \mathrm{y}), \mathrm{y} \in \mathrm{S}^{\mathrm{n}}$, is a symmetric Nash-equilibrium if $\mathrm{x}^{\mathrm{T}} \mathrm{B}$ y $\leq \mathrm{y}^{\mathrm{T}}$ B y for all $x \in S^{n}$. Furthermore, the mixed strategy combination $(y, y), y \in S^{n}$, is an evolutionary $\underline{\text { stable strategy }}$ if $\mathrm{x} \in \mathrm{S}^{\mathrm{n}}$ implies $\mathrm{x}^{\mathrm{T}} \mathrm{B} \mathrm{y} \leq \mathrm{y}^{\mathrm{T}} \mathrm{B} \mathrm{y}$, and additionally if $\mathrm{x} \in \mathrm{S}^{\mathrm{m}} \backslash\{\mathrm{y}\}$ and $\mathrm{x}^{\mathrm{T}} \mathrm{B} \mathrm{y}$ $=\mathrm{y}^{\mathrm{T}} \mathrm{B} \mathrm{y}$, then $\mathrm{x}^{\mathrm{T}} \mathrm{B} \mathrm{x}<\mathrm{y}^{\mathrm{T}} \mathrm{B} \mathrm{x}$. The following proposition establishes the connections between the saturated equilibria of Equation (4), and the Nash-equilibria of a 'derived' bimatrix game.

Proposition 2.6. Let $A$ be an $(m+1) \times(m+1)$ matrix, let $C=\left[s^{1}, s^{2}, \ldots, s^{n+1}\right]$ an $(m+1) \times(n+1)$ matrix, with $s^{k} \in S^{m}$ for all $k \in I^{n+1}$. Then, the following two statements are equivalent:

i) $y$ is a saturated equilibrium of the relative fitness function given by (4),

ii) $(y, y)$ is a Nash equilibrium of the symmetric bimatrix game $\left(C^{T} A C, C^{T} A^{T} C\right)$.

In the traditional models in evolutionary game theory, it usually holds that $\mathrm{m}=\mathrm{n}$, and $\mathrm{s}^{\mathrm{j}}=$ $e_{j}$ for all $\mathrm{j} \in \mathrm{I}^{\mathrm{n}+1}$. In that case $\mathrm{C}^{\mathrm{T}} \mathrm{AC}=\mathrm{A}$, and any saturated equilibrium y corresponds with a symmetric Nash equilibrium of $\left(\mathrm{A}, \mathrm{A}^{\mathrm{T}}\right)$, and vice versa. The following shows the connections and, perhaps more importantly, discrepancies between strategic equilibria for $\left(\mathrm{A}, \mathrm{A}^{\mathrm{T}}\right)$ and for $\left(\mathrm{C}^{\mathrm{T}} \mathrm{AC}, \mathrm{C}^{\mathrm{T}} \mathrm{A}^{\mathrm{T}} \mathrm{C}\right)$ in general.

Proposition 2.7. Let $A$ be an $(m+1) \times(m+1)$ matrix, let $C=\left[s^{1}, s^{2}, \ldots, s^{n+1}\right]$ an $(m+1) \times(n+1)$ matrix, with $s^{k} \in S^{m}$ for all $k \in I^{n+1}$. Then,

i) if $\left(s^{k}, s^{k}\right)$ is a Nash equilibrium of the bimatrix game $\left(A, A^{T}\right)$, then $\left(e_{k}, e_{k}\right)$ is a Nash equilibrium of the bimatrix game $\left(C^{T} A C, C^{T} A^{T} C\right)$, not conversely,

ii) if $\left(s^{k}, s^{k}\right)$ is an evolutionary stable strategy of the bimatrix game $\left(A, A^{T}\right)$ and $s^{k} \notin \operatorname{conv}\left\{s^{j} \mid j \neq k\right\}$, then $\left(e_{k}, e_{k}\right)$ is an evolutionary stable strategy of the symmetric bimatrix game $\left(C^{T} A C, C^{T} A^{T} C\right)$, not conversely.

Propositions 2.6 and 2.7 clearly imply that the result of Nachbar (1990) regarding limit points of interior trajectories under 'evolutionary' dynamics being Nash equilibria, cannot effortlessly be generalized to evolutionary games where mixed strategies are inherited. 
In Van Damme (1991), an evolutionary stable strategy of a symmetric bimatrix game $\left(A, A^{T}\right)$ is characterized as follows. The strategy $y \in S^{n}$ is an evolutionary stable strategy, if and only if for a relative fitness function given by (4), with $\mathrm{m}=\mathrm{n}$ and $\mathrm{C}=\left[\mathrm{e}_{1}, \mathrm{e}_{2}, \ldots, \mathrm{e}_{\mathrm{n}+1}\right]$, there exists a(n open) neighborhood $U \subseteq S^{n}$ of y such that

$$
y^{T} A x>x^{T} A x \quad \text { for all } x \in U \backslash\{y\}
$$

Since Eq. (4) reduces to $f_{k}(x)=\left(e_{k}\right)^{T} A x-x^{T} A x$ for all $k \in I^{n+1}$, and $x \in S^{n}$, Eq. (5) can be written alternatively as

$$
\mathrm{y}^{\mathrm{T}} \mathrm{f}(\mathrm{x})>0 \quad \text { for all } \mathrm{x} \in \mathrm{U} \backslash\{\mathrm{y}\}
$$

Note the similarity of Equations (3) and (5'), where the functions $f$ and $G$ are perfectly interchangeable, since by complementarity $x^{T} f(x)=0$ for all $x \in S^{n}$. We will focus now on the question whether (5') implies dynamical stability or not.

If (5') holds in an open neighborhood $U \subseteq S^{n}$ of a saturated equilibrium y for an arbitrary relative fitness function $\mathrm{f}$, then it follows easily that no saturated equilibrium exists in $U \backslash\{y\}$. We call such a state a generalized evolutionary stable state. For a population consisting of two subgroups, the asymptotically stable fixed points, the evolutionary stable equilibria and generalized evolutionary stable states concur for arbitrary sign-compatible dynamics. This leads to the following, where GESS denotes the set of all generalized evolutionary stable states.

Corollary 2.4. For $n=1, E S E=A S F P=G E S S$.

The following may be quite useful in higher dimensions, i.e., if there exist more than two subgroups. For a saturated equilibrium $y$, let $\mathrm{H}_{\mathrm{y}}: \mathrm{S}^{\mathrm{n}} \rightarrow \mathbb{R}^{\mathrm{n}+1}$, be given by

$$
H_{y}(x)=(y-x)^{T}(G(x)-f(x)) .
$$

Proposition 2.8. If for a saturated equilibrium y there exists an open neighborhood $U \subseteq S^{n}$, such that $H_{y}(x)<(>) 0$ for all $\left.x \in U \backslash y\right\}$, then ' $y$ is an evolutionary stable equilibrium' 
implies 'y is a generalized evolutionary stable state' ('y is a generalized evolutionary stable state' implies 'y is an evolutionary stable equilibrium').

Obviously, each evolutionary stable strategy of the bimatrix game $\left(\mathrm{A}, \mathrm{A}^{\mathrm{T}}\right)$ is a generalized evolutionary stable state for the relative fitness function given by (4), with $\mathrm{m}=\mathrm{n}$ and $\mathrm{C}=$ $\left[\mathrm{e}_{1}, \mathrm{e}_{2}, \ldots, \mathrm{e}_{\mathrm{n}+1}\right]$, and vice versa. However, the results of Taylor and Jonker (1978), Zeeman (1981), namely that evolutionary stability implies asymptotical stability for the replicator dynamics, need not hold for arbitrary sign-compatible dynamics. If $(y-x)^{\mathrm{T}} \mathrm{G}(\mathrm{x})<0<\mathrm{y}^{\mathrm{T}} \mathrm{f}(\mathrm{x})$ for all $\mathrm{x} \neq \mathrm{y}$ in an open neighborhood $\mathrm{U}$ of $\mathrm{y}$, then $\mathrm{y}$ is a dynamically unstable generalized evolutionary state. By the converse argument, it follows that an evolutionary stable equilibrium need not be a generalized evolutionary stable state for $n>1$.

\section{On the number of fixed points and their stability}

First, we show (mathematical) analogies between certain concepts developed in this paper, and in general equilibrium theory. We proceed by applying several well-known results in general equilibrium theory to our evolutionary model. Let $\mathbb{R}^{\mathrm{n}+1}=\left\{\mathrm{x} \in \mathbb{R}^{\mathrm{n}+1} \backslash\{\mathbf{0}\} \mid \mathrm{x}_{\mathrm{i}} \geq 0\right.$ for all $\left.\mathrm{i} \in \mathrm{I}^{\mathrm{n}+1}\right\}$ denote the set of all prices of $\mathrm{n}+1$ economic goods, where $\mathrm{x} \in \mathbb{R}^{\mathrm{n}+1}$ is an $(\mathrm{n}+1)$ vector of prices, and $\mathrm{x}_{\mathrm{j}}$ denotes the price of good $\mathrm{j} \in \mathrm{I}^{\mathrm{n}+1}$. An excess demand function is a continuous function $\mathrm{f}: \mathbb{R}^{\mathrm{n}+1} \rightarrow \mathbb{R}^{\mathrm{n}+1}$ satisfying:

(i) Walras' law, i.e., $\mathrm{x}^{\mathrm{T}} \mathrm{f}(\mathrm{x})=0$ for all $\mathrm{x} \in \mathbb{R}^{\mathrm{n}+1}$, and

(ii) (Positive) Homogeneneity of degree zero in $\mathrm{x} \in \mathbb{R}^{\mathrm{n}+1}$, i.e. for all $\alpha>0$ it holds that $\mathrm{f}(\alpha \mathrm{x})=\alpha^{0} \mathrm{f}(\mathrm{x})$, and

(iii) (Weak) Desirability of all goods, i.e. $\mathrm{f}_{\mathrm{i}}(\mathrm{x}) \geq 0$, whenever $\mathrm{x}_{\mathrm{i}}=0$.

Strong desirability is formalized by $\mathrm{f}_{\mathrm{i}}(\mathrm{x})>0$, whenever $\mathrm{x}_{\mathrm{i}}=0$. If Property (iii) is dropped, then the function $\mathrm{f}$ is called a generalized excess demand function. Sonnenschein (1972, 1973), Mantel (1974), and Debreu (1974) have shown that any continuous function satisfying complementarity can be approximated arbitrarily closely by an aggregate excess demand 
function derived from a pure exchange economy with utility maximizing agents.

Homogeneity of degree zero of the (generalized) excess demand functions allows restricting analysis to normalizations of the price space, $P^{p}=\left\{x \in \mathbb{R}^{n+1} \mid\|x\|_{p}=1\right\}$ with $p$ $\in \mathbb{N}$, where Property (ii) becomes void. Note that these sets are compact, whereas $\mathbb{R}^{n+1}{ }_{+}$is neither closed, nor bounded. A relative fitness function is mathematically equivalent to a generalized excess demand function for an economy with prices normalized to $\mathrm{S}^{\mathrm{n}}$.

A Walrasian equilibrium is characterized by a price vector $\mathrm{y} \in \mathbb{R}^{\mathrm{n}+1}+$ which satisfies $\mathrm{f}(\mathrm{y}) \leq \mathbf{0}$, where $\mathrm{f}$ is a generalized excess demand function. At a Walrasian equilibrium, there exists no good of which the aggregate demand exceeds the aggregate supply. The saturated equilibrium and the Walrasian equilibrium for a pure exchange economy with prices normalized to $\mathrm{S}^{\mathrm{n}}$, are mathematical parallels. The standard price adjustment process in economic literature is the Walrasian tâtonnement process, formalized as a set of differential equations by Samuelson (1947). For more general tâtonnement processes which we will describe below, we refer to Uzawa (1961). Let $x \in \mathbb{R}^{n+1}$, be an $(n+1)$-vector of prices, and let $\mathrm{f}: \mathbb{R}^{\mathrm{n}+1}+\rightarrow \mathbb{R}^{\mathrm{n}+1}$ be a generalized excess demand function, then a tâtonnement process is defined by

$$
\mathrm{dx} / \mathrm{dt}=\quad \mathrm{F}(\mathrm{x}) \quad \text { for all } \mathrm{x} \in \mathbb{R}^{\mathrm{n}+1},
$$

where $\mathrm{F}: \mathbb{R}^{\mathrm{n}+1}{ }_{+} \rightarrow \mathbb{R}^{\mathrm{n}+1}$ satisfies: $\mathrm{F}_{\mathrm{i}}(\mathrm{x})=0$ if $\mathrm{x}_{\mathrm{i}}=0$ and $\mathrm{f}_{\mathrm{i}}(\mathrm{x})<0$, and $\operatorname{sign} \mathrm{F}_{\mathrm{i}}(\mathrm{x})=\operatorname{sign} \mathrm{f}_{\mathrm{i}}(\mathrm{x})$ otherwise. The tâtonnement process proposed by Samuelson (1947) is given by:

$$
\mathrm{dx}_{\mathrm{i}} / \mathrm{dt}= \begin{cases}0 & \text { if } \mathrm{x}_{\mathrm{i}}=0 \text { and } \mathrm{f}_{\mathrm{i}}(\mathrm{x})<0, \\ \mathrm{f}_{\mathrm{i}}(\mathrm{x}) & \text { otherwise. }\end{cases}
$$

Hence, the change in price of each good with a positive price, corresponds in sign with its excess demand, moreover the change is proportional to its excess demand. An interesting case is the 'weak axiom of revealed preferences'-case, where for a Walrasian equilibrium y, Equation (5') holds for all positive price vectors $\mathrm{x}$ with length equal to $\mathrm{y}$. Then, each trajectory under Samuelson's process starting from such a price vector, converges to $\mathrm{y}^{2}$.

Sign-compatible population dynamics are mathematically equivalent to a subclass of

\footnotetext{
${ }^{2}$ The proof is well established, cf. Varian (1978) where a slightly more general proposition is proven.
} 
the tâtonnement processes on the unit simplex. The additional requirements for this subclass with respect to the function $F$ are continuity, $\sum_{i} F_{i}(x)=0$ for all $x \in S^{n}$, and $F_{i}(x)=0$, whenever $x_{i}=0$. An example of such a tâtonnement process on $S^{n}$ is:

$$
\mathrm{dx}_{\mathrm{i}} / \mathrm{dt}=\quad \mathrm{x}_{\mathrm{i}} \mathrm{f}_{\mathrm{i}}(\mathrm{x}) \quad \text { for all } \mathrm{i} \in \mathrm{I}^{\mathrm{n}+1} \text {. }
$$

Under this process, the change in the price for each good corresponds in sign with, and is proportional to, the value of its excess demand. The reader familiar with evolutionary dynamics, will quickly recognize the similarity of this process to the replicator dynamics.

At least one saturated equilibrium exists for arbitrary relative fitness functions, and the vertices of the unit simplex are fixed points of sign-compatible dynamics. Generically, each of the $2^{\mathrm{n}+1}-2$ faces of the unit simplex contains a fixed point of sign-compatible dynamics. It is even not difficult to construct several essentially different examples where there exists a continuum of saturated equilibria. If the set of saturated equilibria contains more than one element, then not each saturated equilibrium can be asymptotically stable. Conversely however, uniqueness of a saturated equilibrium is not sufficient even for stability.

If the condition of the following proposition is fulfilled, then there exists a facet or there exist certain facets of the unit simplex which do not contain a saturated equilibrium.

Proposition 3.1. If $k \in K \subseteq I^{n+1}$ implies $f_{k}(x)>0$ whenever $x_{k}=0$, then $\delta>0$ exists, such that for all trajectories $\{x(t)\}_{t \geq 0}: \operatorname{Liminf}_{t \rightarrow \infty} x_{k}(t) \geq \delta$ provided $x_{k}(0)>0$, for all $k \in K$.

This proposition implies that each subgroup in $\mathrm{K}$ will 'survive', even if the system is subjected to a small incidental shock. For $|K| \geq 2$, none of the vertices of the unit simplex is a saturated equilibrium. If the condition of Proposition 3.1 holds for $\mathrm{K}=\mathrm{I}^{\mathrm{n}+1}$, this is sufficient for permanence of the system (cf. Hofbauer and Sigmund, 1988). Permanence implies that all saturated equilibria are in the interior of the state space, and that all subgroups 'survive' in the long run, moreover their population share is bounded from below by $\delta$. Permanence corresponds with strong desirability of all goods in a pure exchange economy.

A setting where slightly more precise statements can be made about the number of fixed points of sign-compatible dynamics, is the situation where all saturated equilibria are regular, meaning that the determinant of the Jacobian matrix of the relative fitness function 
at such a point, exists and is nonzero. It follows from Debreu (1970) that if all saturated equilibria are regular, then each is locally unique, and their number is finite since the state space is compact. Moreover, there exists an odd number of equilibria (cf. Dierker, 1972, Hofbauer and Sigmund, 1988).

Another setting is the following. We call a system strongly cooperative (competitive) ${ }^{3}$ if for a differentiable relative fitness function $\mathrm{f}$,

$$
\partial \mathrm{f}_{\mathrm{i}}(\mathrm{x}) / \partial \mathrm{x}_{\mathrm{j}}>(<) 0 \text { for all } \mathrm{i} \neq \mathrm{j} \text { and all } \mathrm{x} \in \text { int } \mathrm{S}^{\mathrm{n}} \text {. }
$$

Arrow et al. (1959) consider the case that all goods in an economy are strong gross substitutes. The conditions for strong cooperativeness and gross substitutability are mathematically equivalent. The following lemma from Arrow et al. (1959), is used in the proof of the ensuing proposition.

Lemma 3.1. If all commodities are strong gross substitutes, the excess demand function satisfies homogeneity of degree zero, and there exists a positive equilibrium price vector, then this price vector is uniquely (up to a scalar multiple) determined.

Proposition 3.2. For a strongly cooperative system, if there exists an interior saturated equilibrium, then it is the unique interior saturated equilibrium.

For a strongly competitive evolutionary system with relative fitness function $f$, the system with relative fitness function $-\mathrm{f}$ is strongly cooperative. Proposition 3.2 shows that if an interior saturated equilibrium y exists for the system with relative fitness function $-f$, then $y$ is the unique interior saturated equilibrium. Hence, $y$ is the unique interior saturated equilibrium for $\mathrm{f}$.

The following lemma is a straightforward application of a theorem of Uzawa (1961). It links the conditions for uniqueness of a saturated equilibrium with conditions for asymptotical stability.

\footnotetext{
${ }^{3}$ Hofbauer and Sigmund (1988) use the terms cooperative and competitive for slightly different evolutionary systems. However, for the replicator dynamics, sgn $\partial \mathrm{G}_{\mathrm{i}}(\mathrm{x}) / \partial \mathrm{x}_{\mathrm{j}}=\operatorname{sgn} \partial \mathrm{f}_{\mathrm{i}}(\mathrm{x}) / \partial \mathrm{x}_{\mathrm{j}}$ for all interior states.
} 
Lemma 3.2. If, for a strongly cooperative system, there exists an interior saturated equilibrium, then each trajectory of sign-compatible dynamics from the interior of $S^{n}$, converges to it.

By a (similar) converse argument as above, it follows that if a system is strongly competitive, the interior saturated equilibrium is dynamically unstable. Uniqueness of interior saturated equilibria need not hold, if strong cooperativeness (competitiveness) is weakened to $\partial \mathrm{f}_{\mathrm{i}}(\mathrm{x}) / \partial \mathrm{x}_{\mathrm{j}}$ $\geq(\leq) 0$ for all $\mathrm{i} \neq \mathrm{j}$ and for all $\mathrm{x} \in \mathrm{S}^{\mathrm{n}}$ in (6). However, all trajectories for sign-compatible dynamics starting in the interior of $S^{n}$ converge to some fixed point (cf. Uzawa, 1961).

\section{Evolutionary modelling}

Relative fitness function

Complementarity of the relative

fitness function

Saturated equilibrium

Sign-compatible population dynamics Permanence

Strongly cooperative system

(Generalized) evolutionary stable state

\section{Pure exchange economies with prices normalized} to the unit simplex

\author{
Excess demand function \\ Walras' Law \\ Walrasian equilibrium \\ tâtonnement processes \\ Desirability of all goods \\ Gross substitutability of all goods \\ Weak axiom of revealed preferences
}

Table I. Mathematical similarities shown.

If a strongly cooperative system is permanent, then Proposition 3.1 implies that every saturated equilibrium lies in int $\mathrm{S}^{\mathrm{n}}$, whereas Proposition 3.2 implies that there exists only one equilibrium in int $\mathrm{S}^{\mathrm{n}}$. By Lemma 3.2 this point is asymptotically stable, hence $|\mathrm{SAT}|=$ $\mid$ ASFP $\mid=1$, where SAT denotes the set of all saturated equilibria. If for a relative fitness function $f$, the evolutionary system under $-f$ is permanent, then the $n+1$ vertices of the $n$ dimensional unit simplex are strict saturated equilibria. Hence, in that case $\mid$ ESE $|\geq|$ SSAT $\mid$ $=\mathrm{n}+1$. If, the system is additionally strongly competitive, then by Proposition 3.2 and Lemma 3.2 exactly one interior saturated equilibrium exists, which is dynamically unstable. Therefore $|\mathrm{SAT}|>|\mathrm{ASE}| \geq|\mathrm{SSAT}|=\mathrm{n}+1$. 


\section{Finding fixed points of sign-compatible dynamics}

Finding an arbitrary fixed point of sign-compatible dynamics is a trivial problem, since the $\mathrm{n}+1$ vertices of the $\mathrm{n}$-dimensional unit simplex are fixed points for all sign-compatible dynamics. It was shown in Section 2 that each strict saturated equilibrium is a vertex of the state space, and that such a strict saturated equilibrium is an evolutionary stable equilibrium. It need however not be that any vertex of the state space is saturated, in which case a check of the vertices can only yield dynamically unstable fixed points. For predictive purposes the unstable fixed points are of little relevance, since the slightest disturbance of the dynamical system may move the system away from such a fixed point. Though we did not specificly model such disturbances, two observations are in order. In real-world dynamical systems disturbances may be caused by environmental influences. Secondly, it is worth keeping in mind that the deterministic differential equations of Eq. (2), are approximations of very complicated stochastic processes, see e.g. Gilboa and Matsui (1992), Boylan (1992) on the topic. However, some residual stochastic noise in the dynamical system may not be unrealistic.

Finding $\mathrm{y} \in \mathrm{S}^{\mathrm{n}}$ for which $\mathrm{z}(\mathrm{y}) \leq \mathbf{0}$ for a continuous function $\mathrm{z}: \mathrm{S}^{\mathrm{n}} \rightarrow \mathbb{R}^{\mathrm{n}+1}$ satisfying complementarity, is called a nonlinear complementarity problem with respect to z. Many methods have been suggested to solve the nonlinear complementarity problem, which may provide solutions to find saturated equilibria for some relative fitness functions, e.g., Smale (1976). Smale's Global Newton method is extremely efficient when started near certain Walrasian equilibria. It need however not converge to a Walrasian equilibrium when started in an arbitrary state (cf. Keenan, 1981). We are interested in methods which solve the nonlinear complementarity problem with respect to arbitrary relative fitness functions. The results of Saari and Simon (1978) and Saari (1985) imply that for this purpose, one should rely on scarf-type methods (Scarf 1973, Kuhn 1968,1969). For alternative computational methods we refer to e.g., Eaves (1972), Todd (1976) and improvements. For an overview on the nonlinear complementarity problem, related problems, algorithms and applications, see the excellent survey of Harker and Pang (1990).

One class of efficient simplicial algorithms originated with Van der Laan and Talman (1979). This so-called variable dimension restart algorithm was designed to solve the problem 
of finding a Walrasian equilibrium for a pure exchange economy where the excess demand function fulfills strong desirability. Van der Laan et al. (1987) formulated an algorithm to solve the more general nonlinear complementarity problem on the product space of a finite number of unit simplices. For a survey on variable dimension restart algorithms, we refer to Van der Laan and Talman (1987). In the following, we describe the algorithm of Doup et al. (1987) as an illustration. To simplify the exposure below considerably and remaining within the context of our model, we will limit ourselves to the case where the state space is the unit simplex, and the arbitrary starting point of the algorithm lies in its relative interior.

Let $\mathrm{z}: \mathrm{S}^{\mathrm{n}} \rightarrow \mathbb{R}^{\mathrm{n}+1}$ satisfy continuity and complementarity. Let in the sequel, $\mathrm{v} \in$ int $\mathrm{S}^{\mathrm{n}}$ denote the arbitrary starting point of the algorithm. The algorithm subdivides the unit simplex into subsets of variable dimension for sign vectors $s$ in $\mathbb{R}^{\mathrm{n}+1}$ with components $\mathrm{s}_{\mathrm{j}} \in\{-1,0,+1\}$, depending on v. For a sign vector s, let

$$
\begin{aligned}
& \mathrm{I}^{-}(\mathrm{s})=\left\{\mathrm{i} \in \mathrm{I}^{\mathrm{n}+1} \mid \mathrm{s}_{\mathrm{i}}=-1\right\}, \\
& \mathrm{I}^{0}(\mathrm{~s})=\left\{\mathrm{i} \in \mathrm{I}^{\mathrm{n}+1} \mid \mathrm{s}_{\mathrm{i}}=0\right\}, \\
& \mathrm{I}^{+}(\mathrm{s})=\left\{\mathrm{i} \in \mathrm{I}^{\mathrm{n}+1} \mid \mathrm{s}_{\mathrm{i}}=+1\right\} .
\end{aligned}
$$

We assume from now on that at least one component of every sign vector is equal to +1 and at least one is equal to -1 . Each sign vector $s$ induces a $t$-dimensional subset of $S^{n}$ with $t=$ $\left|\mathrm{I}^{0}(\mathrm{~s})\right|+1$, as follows.

Definition 4.1 Let $s$ be a sign vector with $\left|I^{+}(s)\right|,\left|I^{-}(s)\right|>0$, let $t=\left|I^{0}(s)\right|+1$, and let $v$ $\in$ int $S^{n}$. Then the t-dimensional subset $A(s)$ of $S^{n}$, is given by

$$
\begin{aligned}
& A(s)=\left\{x \in S^{n} \mid \quad x_{i}=a v_{i} \quad \text { if } i \in I^{+}(s)\right. \text {, } \\
& x_{i}=b v_{i} \quad \text { if } i \in I^{-}(s) \text {, } \\
& \left.x_{i} \in\left[b v_{i}, a v_{i}\right] \text { if } i \in I^{0}(s) \text {, with } 0 \leq b \leq 1 \leq a\right\} \text {. }
\end{aligned}
$$

See Figure 3 for an illustration. The boundary of a t-dimensional set A(s) with $t>1$, consists of the (t-1)-dimensional sets $A\left(s^{\prime}\right)$ with $s^{\prime}{ }_{j} \neq 0$ for precisely one $j \in I^{0}(s)$ and $s^{\prime}{ }_{i}=s_{i}$ for all $\mathrm{i} \neq \mathrm{j}$, and the intersection of $\mathrm{A}(\mathrm{s})$ with boundary face $\mathrm{S}^{\mathrm{n}}\left(\mathrm{I}^{-}(\mathrm{s})\right)$.

Next, each subset $A(s)$ of $S^{n}$ is triangulated, i.e., subdivided into t-dimensional simplices, $\mathrm{t}=\left|\mathrm{I}^{0}(\mathrm{~s})\right|+1$. For a $\mathrm{t}$-simplex $\sigma$ with vertices $\mathrm{y}^{1}, \ldots, \mathrm{y}^{\mathrm{t}+1}$, a $\underline{\mathrm{k} \text {-face, }} \mathrm{k} \leq \mathrm{t}-1$, is the convex hull of $k+1$ vertices of $\sigma$. A k-face of $\sigma$ is called a facet of $\sigma$ if $k=t-1$. Firstly, the union of all simplices with dimension $\mathrm{t}=\mathrm{n}$, is equal to $\mathrm{S}^{\mathrm{n}}$. Furthermore, for each pair of $\mathrm{t}$ - 
dimensional simplices, $1 \leq \mathrm{t} \leq \mathrm{n}$, the intersection is either empty or a common face of both, which in itself is $(\mathrm{t}-\mathrm{k})$-dimensional, $1 \leq \mathrm{k} \leq \mathrm{t}$. We refer to Figure 4 for an illustration.

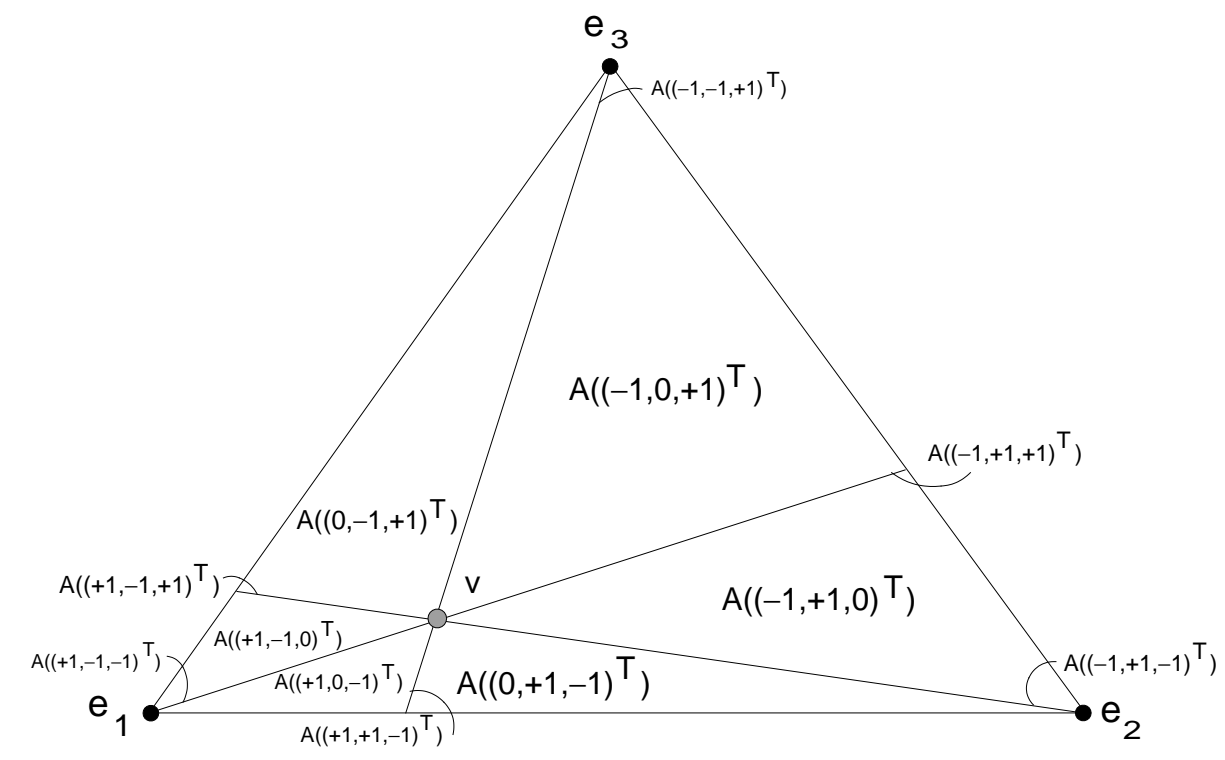

Figure 3. The subdivision of $S^{n}, n=2$, into sets $A(s)$ of dimension $t=\left|I^{0}(s)\right|+1,1 \leq t \leq n+1$.

Definition 4.2 A t-simplex $\sigma\left(y^{l}, \ldots, y^{t+1}\right), 1 \leq t \leq n$, is $\underline{\text { s-complete }}$ if the system of $n+2$ linear equations

$$
\sum_{\mathrm{i}=1}^{\mathrm{t}+1} \lambda_{\mathrm{i}}\left(\begin{array}{c}
\mathrm{z}\left(\mathrm{y}^{\mathrm{i}}\right) \\
1
\end{array}\right)-\sum_{\mathrm{h} \notin \mathrm{I}^{\mathrm{O}}(\mathrm{s})} \mu_{\mathrm{h}} \mathrm{s}_{\mathrm{h}}\left(\begin{array}{c}
\mathrm{e}_{\mathrm{h}} \\
0
\end{array}\right)=\left(\begin{array}{l}
\mathbf{0} \\
1
\end{array}\right),
$$

has a nonnegative solution $\lambda{ }_{i}^{*}, i=1, \ldots, t+1$, and $\mu^{*}{ }_{h}, h \notin I^{0}(s)$.

We assume that for each solution of the system of Definition 4.2, at most one of the variables $\lambda_{\mathrm{i}}{ }^{*}$ 's and $\mu_{\mathrm{h}}{ }^{*}$ 's is equal to zero. Under this nondegeneracy assumption, each s-complete tsimplex has a line segment of solutions $\left(\lambda^{*}, \mu^{*}\right)$, since the system of Definition 4.2 has $n+2$ linear equations and $n+3$ variables. An endpoint of such a line segment is called a basic

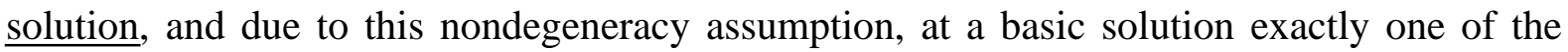
variables $\left(\lambda^{*}, \mu^{*}\right)$ is equal to zero.

Definition 4.3 Let $\sigma\left(y^{l}, \ldots, y^{t+1}\right)$ be a $t$-simplex, $1 \leq t \leq n$, let $x \in \sigma\left(y^{l}, \ldots, y^{t+1}\right)$. Let $\lambda_{l}, \ldots, \lambda_{t+1}$ be the unique weights satisfying $x=\sum_{i} \lambda_{i} y^{i}, \lambda_{i} \geq 0$ for all $i \in I^{t+1}$, and $\Sigma_{i} \lambda_{i}=1$. Then the 
piecewise linear approximation $Z$ of $z$ at $x$, is given by $Z(x)=\sum_{i} \lambda_{i} z\left(y^{i}\right)$.

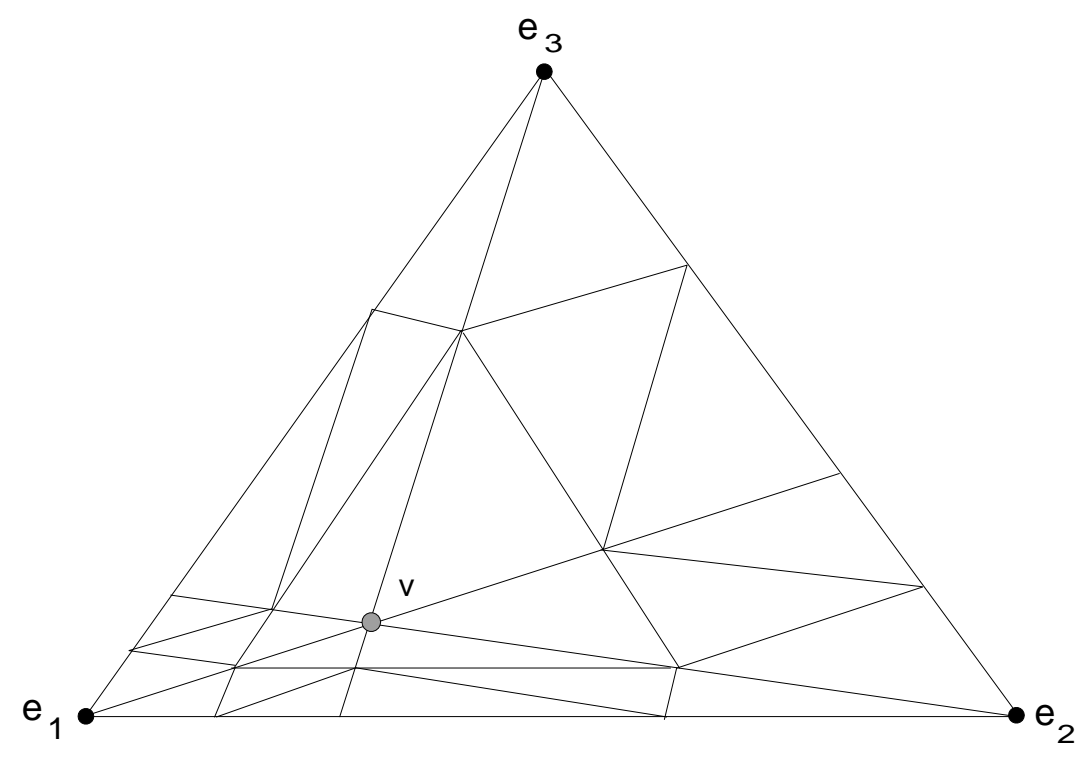

Figure 4. The simplicial subdivision of $S^{n}$ for $n=2$, and of each subset $A(s)$ for $m=2$. Each $t$-dimensional set $\mathrm{A}(\mathrm{s})$ of $\mathrm{S}^{\mathrm{n}}, 1 \leq \mathrm{t} \leq \mathrm{n}+1$, is subdivided into $\mathrm{m}^{\mathrm{t}} \mathrm{t}$-dimensional simplices.

The line segment of solutions $\left(\lambda^{*}, \mu^{*}\right)$ of the linear system of Definition 4.2, induces a line segment of points $\mathrm{x}=\sum_{\mathrm{i}} \lambda{ }^{*} \mathrm{y}^{\mathrm{i}}$ in the s-complete simplex $\sigma$. Each line segment of points has two end points, and each end point corresponds with exactly one of the basic solutions. For each point $\mathrm{x}$ of this line segment of points in $\sigma$, it holds that $\operatorname{sign} \mathrm{Z}(\mathrm{x})=\operatorname{sign}\left(\sum_{\mathrm{i}} \lambda^{*}{ }_{\mathrm{i}} \mathrm{z}\left(\mathrm{y}^{\mathrm{i}}\right)\right)=$ s. The latter may be confirmed by checking the linear system of Definition 4.2. This line segment of such points, or alternatively the line segment of solutions of the linear system of Definition 4.2, can be followed by making a linear programming pivot step with one of the variables which are zero at an end point. At an end point $x^{*}$, it holds either $\lambda^{*}{ }_{i}=0$ for some $\mathrm{i} \in \mathrm{I}^{\mathrm{t}+1}$ which implies $\mathrm{x}^{*}$ lies in the facet of $\sigma\left(\mathrm{y}^{1}, \ldots, \mathrm{y}^{\mathrm{t}+1}\right)$ opposite vertex $\mathrm{y}^{\mathrm{i}}$, or $\mu^{*}{ }_{\mathrm{h}}=0$ for some $\mathrm{h} \notin \mathrm{I}^{0}(\mathrm{~s})$ which implies $\mathrm{Z}_{\mathrm{h}}\left(\mathrm{x}^{*}\right)=0$.

Now we are ready to describe the algorithm with the concepts just defined. If we happen to have $\mathrm{z}(\mathrm{v})=0$, then we are finished. Otherwise, assume that at the starting point $\mathrm{v},\left|\mathrm{I}^{0}(\mathrm{z}(\mathrm{v}))\right|=0$. If not, we may either take an alternative starting point nearby, or slightly disturb $\mathrm{z}$ at $\mathrm{v}$, such that $\mathrm{z}(\mathrm{v})$ does not contain any components equal to zero. Let in that case, $\mathrm{s}^{0}=\operatorname{sign} \mathrm{z}(\mathrm{v})$ and let $\sigma^{0}\left(\mathrm{y}^{1}, \mathrm{y}^{2}\right)$, where $\mathrm{y}^{1}=\mathrm{v}$, be the unique one-simplex in $\mathrm{A}\left(\mathrm{s}^{0}\right)$ with $\mathrm{v}$ as a vertex. It is readily confirmed that $\sigma^{0}\left(\mathrm{y}^{1}, \mathrm{y}^{2}\right)$ is $\mathrm{s}^{0}$-complete with $\lambda^{*}{ }_{2}=0$ at $\mathrm{y}^{1}=\mathrm{v}$ which is 
one of its basic solutions, and sign $\mathrm{Z}\left(\mathrm{y}^{1}\right)=\mathrm{s}^{0}$. The algorithm starts with this basic solution by making a linear programming pivot step with $\left(\mathrm{z}^{\mathrm{T}}\left(\mathrm{y}^{2}\right), 1\right)^{\mathrm{T}}$ in the system of linear equations of Definition 4.2, and the unique line segment of solutions in $\sigma^{0}\left(\mathrm{y}^{1}, \mathrm{y}^{2}\right)$ is followed to the other basic solution.

In general, if at a basic solution $\mu^{*}{ }_{h}=0$ for some $h \in I^{0}(s)$, then the corresponding point $\mathrm{x}^{\prime}$ is an approximate zero of $\mathrm{z}$ if $\mathrm{s}_{\mathrm{h}}=+1$ and $\left|\mathrm{I}^{+}(\mathrm{s})\right|=1$ or if $\mathrm{s}_{\mathrm{h}}=-1$ and $\left|\mathrm{I}^{-}(\mathrm{s})\right|=$ 1. In the first case $Z\left(x^{\prime}\right) \leq 0$ and in the latter case $Z\left(x^{\prime}\right) \geq 0$. The algorithm terminates with $\mathrm{x}^{\prime}$ as an approximate solution. Otherwise, $\sigma=\sigma\left(\mathrm{y}^{1}, \ldots, \mathrm{y}^{\mathrm{t}+1}\right)$ is also s'-complete and a facet of just one s'-complete $(\mathrm{t}+1)$-simplex $\sigma^{\prime}$ in $\mathrm{A}\left(\mathrm{s}^{\prime}\right)$ with $\mathrm{s}_{\mathrm{h}}{ }_{\mathrm{h}}=0 \neq \mathrm{s}_{\mathrm{h}}$ and $\mathrm{s}_{\mathrm{k}}{ }_{\mathrm{k}}=\mathrm{s}_{\mathrm{k}}$ for all $\mathrm{k} \neq \mathrm{h}$. Then the algorithm continues by making a linear programming pivot step with $\left(\mathrm{z}^{\mathrm{T}}(\mathrm{y}), 1\right)^{\mathrm{T}}$ where $\mathrm{y}$ is the vertex of the $(\mathrm{t}+1)$-simplex $\sigma^{\prime}$ opposite the facet $\sigma$ of $\sigma^{\prime}$.

On the other hand, if, by making an 1.p. pivot step in the system of Definition 4.2 with respect to $\sigma, \lambda^{*}$ j becomes zero for some $\mathrm{j} \in \mathrm{I}^{\mathrm{t}+1}$, then the facet $\tau$ of $\sigma$ opposite the vertex $\mathrm{y}^{\mathrm{j}}$ is also s-complete. If the (t-1)-simplex $\tau$ lies in the boundary bd $\mathrm{A}(\mathrm{s})$ of $\mathrm{A}(\mathrm{s})$, then either $\tau$ lies in the boundary face $S^{n}\left(I^{-}(s)\right)$ of $S^{n}$, or $\tau$ lies in a (t-1)-subset $A\left(s^{\prime}\right)$ with $s^{\prime}{ }_{i} \neq 0$ for precisely one $\mathrm{i} \in \mathrm{I}^{0}(\mathrm{~s})$ and $\mathrm{s}_{\mathrm{k}}{ }_{\mathrm{k}}=\mathrm{s}_{\mathrm{k}}$ for all $\mathrm{k} \neq \mathrm{i}$. In the first case, at the point $\mathrm{x}^{\prime}$ corresponding to the basic solution, $\mathrm{x}_{\mathrm{j}}{ }_{\mathrm{j}}=0$ for all $\mathrm{j}$ with $\mathrm{Z}_{\mathrm{j}}\left(\mathrm{x}^{\prime}\right)<0$, which implies that $\mathrm{x}^{\prime}$ is an approximate solution. In the other case, $\tau$ is the $\mathrm{s}^{\prime}$-complete $(\mathrm{t}-1)$-simplex $\sigma^{\prime}$ in $\mathrm{A}\left(\mathrm{s}^{\prime}\right)$ and the algorithm continues by making an 1.p. pivot step in the system of Definition 4.2 with $\left(\mathrm{s}_{\mathrm{i}} \mathrm{e}^{\mathrm{T}}{ }_{\mathrm{i}}, 0\right)^{\mathrm{T}}$. Finally, if the s-complete facet $\tau$ of $\sigma$ does not lie in bd $\mathrm{A}(\mathrm{s})$, then the algorithm continues by making an 1.p. pivot step in the system of Definition 4.2 with $\left(\mathrm{z}^{\mathrm{T}}(\mathrm{y}), 1\right)^{\mathrm{T}}$, where $\mathrm{y}$ is the vertex of the unique t-simplex adjacent to $\sigma$ sharing the facet $\tau$ with it.

Thus, the algorithm generates a unique sequence of adjacent simplices of varying dimension starting at $\mathrm{v}$. Under the nondegeneracy assumption, no simplex can be generated more than once. Since the number of simplices of the underlying triangulation is finite, the algorithm must terminate within a finite number of steps. Moreover, it terminates with an approximate solution point $x^{\prime}$ for which either $Z\left(x^{\prime}\right) \leq 0$, or $Z_{j}\left(x^{\prime}\right) \geq 0$ for all $j$ with $x_{j}>0$. If $\mathrm{z}\left(\mathrm{x}^{\prime}\right)$ at the approximate solution $\mathrm{x}^{\prime}$ does not satisfy a predetermined accuracy criterium, then algorithm can be restarted in x' with a finer triangulation. Thus, a more accurate approximation of a saturated equilibrium is generally found, and this restarting procedure can be repeated until the approximate solution does satisfy this accuracy criterium.

For computational results, we refer to Doup (1988). The efficiency of the procedure 
can be enhanced greatly by combining the algorithm of Doup et al. (1987) with the Global Newton method (Smale, 1976). At an approximating solution Smale's method may be applied, which near a saturated equilibrium either converges rapidly to a much more accurate approximation of the equilibrium, or diverges. If the latter happens, or if the last found approximation is insufficiently accurate, the variable dimension restart algorithm may be restarted with a finer simplicial subdivision of the state space.

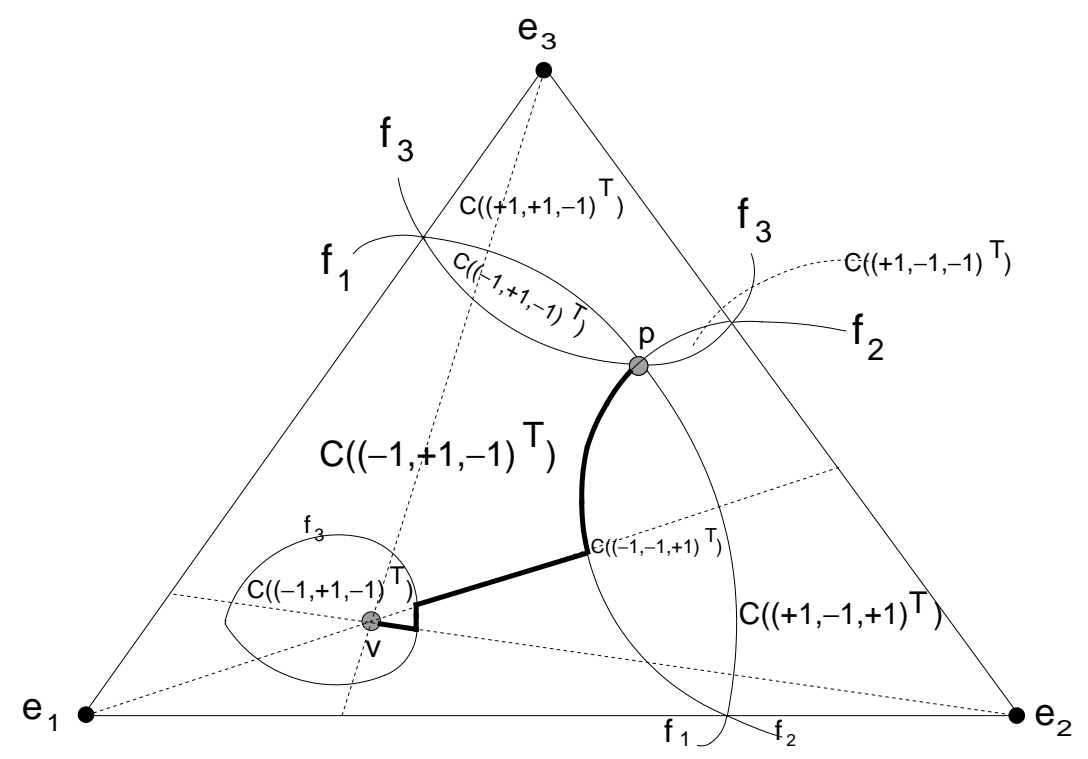

Figure 5. The algorithm follows the heavy curve leading from $\mathrm{v}$ to the saturated equilibrium $\mathrm{p}$. One-dimensional sets for sign vectors containing no zeroes, are indicated by broken straight lines. $\mathrm{C}\left((+1,-1,-1)^{\mathrm{T}}\right)$ refers to a set where $\left(\operatorname{sign} f_{1}(x) \text {,sign } f_{2}(x) \text {, sign } f_{3}(x)\right)^{T}=(+1,-1,-1)^{T} ; f_{1}$ denotes a curve where $f_{1}(x)=0$.

Simulation in order to find equilibria may be quite unpractical. Weissing (1990) shows that for continuous dynamics converging to an interior fixed point, the discrete analogue may spiral outward. Furthermore cycling, i.e., a sequence of points is repeated infinitely, may occur, and detecting cycling requires a vast memory, since it may take many iterations before a sequence of points repeats itself. Additionally, simulated dynamics may cycle, while the real dynamics do not. For games where continuous dynamics admit stable limit cycles only for populations with at least four subgroups, Weissing (1990) shows existence of stable limit cycles for three subgroups for discrete dynamics. For higher-dimensional settings the problems increase in general, and existence of strange attractors, even chaos must be anticipated, and it is unknown what the behavior of the discrete dynamics in the presence of strange attractors, 
is in general. Therefore, although the fixed points of continuous and discrete dynamics concur, the qualitative behaviors of the dynamics may differ, globally or even arbitrarily near a fixed point. Hence, conclusions about (non)convergence of continuous dynamics should not be based on (non)convergence of simulated dynamics, which are discrete approximations of the continuous dynamics by conception.

\section{Conclusions}

We have investigated a very general evolutionary model, while allowing arbitrary continuous fitness functions. We introduced the relative fitness function, which attributes for every state to each subgroup in a population its fitness relative to the average fitness. Such a relative fitness function satisfies complementarity by definition and continuity. We specified a large class of evolutionary population dynamics, called sign-compatible dynamics, under which the change in the population share of each nonextinct subgroup corresponds in sign with the relative fitness of this subgroup. Hence, due to selective pressures the population share of each subgroup which has a fitness which is higher (lower) than the average fitness of the population, increases (decreases).

We examined the saturated equilibrium, showed that the set of saturated equilibria is nonempty for arbitrary relative fitness functions, and that each saturated equilibrium is a fixed point for sign-compatible dynamics. Furthermore, we proved that each stable fixed point is a saturated equilibrium and each trajectory under sign-compatible dynamics from the interior of the state space converges only to a saturated equilibrium. At a saturated equilibrium, each subgroup with positive population share has highest fitness. We introduced the evolutionary stable equilibrium, and the dynamical system has attractive properties in a neighborhood of it. Every trajectory reaching a certain neighborhood of an evolutionary stable equilibrium converges towards it, while the Euclidean distance to the equilibrium strictly decreases monotonically. The dynamic properties of the saturated equilibrium and the evolutionary stable equilibrium suggest that these concepts are adequate dynamic generalizations of the well-known Nash equilibrium and evolutionary stable strategy used in evolutionary game theory. 
An interesting and perhaps surprising by-product of our analysis is that we were able to expose mathematical similarities between relative fitness functions and excess demand functions for pure exchange economies with normalized prices. Both types of functions satisfy continuity and complementarity. Furthermore, a saturated equilibrium corresponds with an economic equilibrium, whereas sign-compatible dynamics for a given relative fitness function correspond with a Walrasian tâtonnement process for an excess demand function (see also Table I). As is widely recognized in economics, we should anticipate any dynamic process on the unit simplex as the outcome of sign-compatible dynamics combined with some relative fitness function. Multiple saturated equilibria may exist even in 'simple' cases, and signcompatible dynamics, may possess stable limit cycles. Even more complex dynamics and attractors must be expected, e.g., tori, and even chaos (e.g., Nowak and Sigmund, 1993).

The generality of our model opens opportunities for evolutionary modelling in various directions. However, the price for the increased generality, is that finding fixed points with certain stability requirements may be quite hard. We propose a two-step method to find saturated equilibria. First all vertices of the unit simplex are examined since each strict saturated equilibrium is necessarily a vertex of the state space, and we have shown that any strict saturated equilibrium is an evolutionary stable equilibrium. To find a saturated equilibrium, a variable dimension restart algorithm for solving the nonlinear complementarity problem, may provide solace. Each such algorithm is globally convergent, which means that it converges to an arbitrarily accurate approximation of a saturated equilibrium within a finite number of steps for arbitrary relative fitness functions while being started from an arbitrary starting point. Research indicates that the algorithm of Doup et al. (1987) is the most efficient variable dimension restart algorithm for the nonlinear complementarity problem. To the best of our knowledge no globally convergent process exists which converges exclusively to stable or asymptotically stable fixed points of the type of dynamics studied in this paper. Suppose namely that such a globally convergent algorithm were to exist, then it would not terminate at all in the case that the model does not possess a stable equilibrium. This would contradict our assumption that the algorithm is globally convergent. Having approximated a saturated equilibrium, further stability analysis may be undertaken. 


\section{APPENDIX}

Proof 2.1 Let $F$ be the point-to-set mapping from $S^{n}$ to the subsets of $S^{n}$, for every $x \in S^{n}$ defined by $F(x)=\operatorname{conv}\left(\left\{e_{j} \mid f_{j}(x)=\max _{i} f_{i}(x), i \in I^{n+1}\right\}\right)$. Then $F$ is uppersemicontinuous, and for every $x \in S^{n}$ the set $F(x)$ is nonempty, convex and compact. From Kakutani (1941), it follows that there exists $y \in S^{n}$, satisfying $y \in F(y)$. Let $c=\max _{i} f_{i}(y)$ and let $T=\left\{k \mid f_{k}(y)=c\right\}$. Since $y_{j}=0$ for all $j \notin T$, we obtain: $0=y^{T} f(y)=\Sigma_{j \in T} y_{j} f_{j}(y)+\Sigma_{j \notin T} y_{j} f_{j}(y)=\Sigma_{j \in T} y_{j} f_{j}(y)=c$.

Proof 2.2 Let $\mathrm{y} \in \mathrm{S}^{\mathrm{n}}$ satisfy $\mathrm{f}(\mathrm{y}) \leq \mathbf{0}$. Then it follows by complementarity that for every $\mathrm{j} \in \mathrm{I}^{\mathrm{n}+1}$ precisely either $\mathrm{y}_{\mathrm{j}}>0$ and $\mathrm{f}_{\mathrm{j}}(\mathrm{y})=0$, or $\mathrm{y}_{\mathrm{j}}=0$ and $\mathrm{f}_{\mathrm{j}}(\mathrm{y}) \leq 0$.

Both imply $\mathrm{G}(\mathrm{y})=\mathbf{0}$ for sign-compatible dynamics.

Proof 2.3 Let $y \in S^{n}$ be a strict saturated equilibrium. Let $j, j \in I^{n+1}$, satisfy $0=f_{j}(y)$. Then $0=\Sigma_{i} y_{i} f_{i}(y) \leq \Sigma_{i \neq j} y_{i} \max _{i \neq j} f_{i}(y)=\left(1-y_{j}\right) \max _{i \neq j} f_{i}(y) \leq 0$. Hence, $y_{j}=1$.

Since $\mathrm{f}$ is continuous, an $\in>0$ and a $\delta>0$ exist, satisfying $\mathrm{f}_{\mathrm{i}}(\mathrm{x})<-\in$ for all $\mathrm{i} \neq \mathrm{j}$ and all $\mathrm{x} \in \mathrm{U}=\left\{\mathrm{u} \in \mathrm{S}^{\mathrm{n}} \mid 1-\mathrm{u}_{\mathrm{j}}<\delta\right\}$. By complementarity $\mathrm{f}_{\mathrm{j}}(\mathrm{x})=-\sum_{\mathrm{i} \neq \mathrm{j}} \mathrm{x}_{\mathrm{i}} \mathrm{f}_{\mathrm{i}}(\mathrm{x}) / \mathrm{x}_{\mathrm{j}}>$ $\left(1-x_{j}\right) \in>0$ for all $x \in U \backslash\{y\}$. Furthermore, $G(y)=\mathbf{0}$ by Proposition 2.2, whereas $\mathrm{x} \in \mathrm{U} \backslash\{\mathrm{y}\}$ implies $\operatorname{sign} \mathrm{G}_{\mathrm{i}}(\mathrm{x}) \leq 0$ for all $\mathrm{i} \neq \mathrm{j}$,

$$
\operatorname{sign} \mathrm{G}_{\mathrm{j}}(\mathrm{x})>0 \text {. }
$$

Let $\mathrm{V}: \mathrm{U} \rightarrow \mathbb{R}$ be defined by $\mathrm{V}(\mathrm{x})=\left(\mathrm{x}_{\mathrm{j}}-1\right)-\Sigma_{\mathrm{i} \neq \mathrm{j}} \mathrm{x}_{\mathrm{i}}$ for all $\mathrm{x} \in \mathrm{U}$.

Clearly, $\mathrm{V}(\mathrm{y})=0$ and $\mathrm{dV}(\mathrm{y}) / \mathrm{dt}=0$, whereas for all $\mathrm{x} \in \mathrm{U} \backslash\{\mathrm{y}\}: \mathrm{V}(\mathrm{x})<0$, and $\partial \mathrm{V}(\mathrm{x}) / \partial \mathrm{x}_{\mathrm{j}}=1$ and $\partial \mathrm{V}(\mathrm{x}) / \partial \mathrm{x}_{\mathrm{i}}=-1, \mathrm{i} \neq \mathrm{j}, \mathrm{dV}(\mathrm{x}) / \mathrm{dt}=\Sigma_{\mathrm{k}} \partial \mathrm{V}(\mathrm{x}) / \partial \mathrm{x}_{\mathrm{k}} \mathrm{G}_{\mathrm{k}}(\mathrm{x})=$ $\mathrm{G}_{\mathrm{j}}(\mathrm{x})-\sum_{\mathrm{i} \neq \mathrm{j}} \mathrm{G}_{\mathrm{i}}(\mathrm{x})>0$ by (7) and (8).

Hence, $\mathrm{V}$ is a strict Lyapunov-function on $\mathrm{U}$, and $\mathrm{y}$ is asymptotically stable.

Proof 2.4 Suppose y is a stable equilibrium and y is not a saturated equilibrium. Then $\mathrm{f}_{\mathrm{j}}(\mathrm{y})>0$ and $\mathrm{y}_{\mathrm{j}}=0$ for some $\mathrm{j} \in \mathrm{I}^{\mathrm{n}+1}$. Since $\mathrm{f}$ is continuous, $\epsilon>0$ and $\delta>0$ exist such that $\mathrm{f}_{\mathrm{j}}(\mathrm{x})>\in$ for all $\mathrm{x} \in \mathrm{U}=\left\{\mathrm{u} \in \mathrm{S}^{\mathrm{n}}\left|\max _{\mathrm{i}}\right| \mathrm{u}_{\mathrm{i}}-\mathrm{y}_{\mathrm{i}} \mid<\delta, \mathrm{i} \in \mathrm{I}^{\mathrm{n}+1}\right\}$. Let $\{\mathrm{z}(\mathrm{t})\}_{t \geq 0}$ be a trajectory with $\mathrm{z}(0) \in \mathrm{U}$ and let $\mathrm{z}_{\mathrm{j}}(0)=\alpha>0$. Since $\mathrm{z}_{\mathrm{j}}(0)=\alpha$ and $\mathrm{f}_{\mathrm{j}}(\mathrm{z}(0))>\in$, it follows that sign $\mathrm{G}_{\mathrm{j}}(\mathrm{z}(0))=+1$, implying $\mathrm{G}_{\mathrm{j}}(\mathrm{z}(0))>0$. Furthermore, $\mathrm{z}_{\mathrm{j}}(\mathrm{t})>\mathrm{z}_{\mathrm{j}}(0)$ and $\mathrm{G}_{\mathrm{j}}(\mathrm{z}(\mathrm{t}))>0\{\mathrm{z}(\mathrm{t})\}_{\mathrm{t} \geq 0} \subset \mathrm{U}$. Then $\left\{\mathrm{z}_{\mathrm{j}}(\mathrm{t})\right\}_{\mathrm{t} \geq 0}$ increases monotonically while $\{\mathrm{z}(\mathrm{t})\}_{\mathrm{t} \geq 0} \subset \mathrm{U}$. Hence, there exists $\mathrm{t}^{*}>0$ such that $\max _{\mathrm{i}}\left|\mathrm{z}_{\mathrm{i}}\left(\mathrm{t}^{*}\right)-\mathrm{y}_{\mathrm{i}}\right|=\delta, \mathrm{i} \in \mathrm{I}^{\mathrm{n}+1}$, thus $\mathrm{z}\left(\mathrm{t}^{*}\right) \notin \mathrm{U}$. This contradicts stability of $\mathrm{y}$.

Proof 2.5 a) ESE $\subseteq$ ASE. Let y be an evolutionary stable equilibrium and let $\mathrm{U} \subset \mathrm{S}^{\mathrm{n}}$ be the open neighborhood of $\mathrm{y}$ where (3) holds. Let $\mathrm{V}: \mathrm{S}^{\mathrm{n}} \rightarrow \mathbb{R}$ be given by $\mathrm{V}(\mathrm{x})=$ $-1 / 2 \Sigma_{\mathrm{i}}\left(\mathrm{y}_{\mathrm{i}}-\mathrm{x}_{\mathrm{i}}\right)^{2}$, then $\mathrm{V}(\mathrm{y})=0$ and $\mathrm{dV}(\mathrm{y}) / \mathrm{dt}=0$, for all $\mathrm{x} \in \mathrm{U} \backslash\{\mathrm{y}\}: \mathrm{V}(\mathrm{x})<0$ and $\mathrm{dV}(\mathrm{x}) / \mathrm{dt}=\Sigma_{\mathrm{i}} \partial \mathrm{V}(\mathrm{x}) / \partial \mathrm{x}_{\mathrm{i}} \mathrm{dx} \mathrm{x}_{\mathrm{i}} / \mathrm{dt}=\Sigma_{\mathrm{i}}\left(\mathrm{y}_{\mathrm{i}}-\mathrm{x}_{\mathrm{i}}\right) \mathrm{G}_{\mathrm{i}}(\mathrm{x})=\mathrm{y}^{\mathrm{T}} \mathrm{G}(\mathrm{x})-\mathrm{x}^{\mathrm{T}} \mathrm{G}(\mathrm{x})>0$. This means that $\mathrm{V}$ is a strict Lyapunov-function on $\mathrm{U}$, hence $\mathrm{y}$ is asymptotically stable.

b) $\mathrm{SNTE} \subseteq$ ESE. Let $\mathrm{y}=\mathrm{e}_{\mathrm{j}}, \mathrm{j} \in \mathrm{I}^{\mathrm{n}+1}$ be a strict saturated equilibrium, then from the proof of Proposition 2.3, it follows that there exists a neighborhood $U$ such that (7) and (8) hold in $U \backslash\{y\}$. Then, $x \in U \backslash\{y\}$ implies $\left(y_{j}-x_{j}\right) G_{j}(x)>0$, as well as $\left(y_{i}-x_{i}\right) G_{i}(x) \geq 0$ for all $i \neq j$. Hence, $(y-x)^{T} G(x)>0$ for all $x \in U \backslash\{y\}$.

Proof 2.6 Note that (4) can be rewritten as:

$f_{k}(x)=\left(e_{k}\right)^{T}\left(C^{T} A C\right) x-x^{T}\left(C^{T} A C\right) x$ for all $x \in S^{n}, k \in I^{n+1}$.

Let $y$ be a saturated equilibrium for the relative fitness function $\mathrm{f}$ given by (4) or (4'). 
Then $y_{j}>0$ implies $f_{j}(y)=0=\max _{i} f_{i}(y)$, hence $e_{j}^{T}\left(C^{T} A C\right) y=\max _{i} e_{i}^{T}\left(C^{T} A C\right) y$. Furthermore, $e_{k}^{T}\left(C^{T} A C\right) y<\max _{i} e_{i}^{T}\left(C^{T} A C\right) y$ implies $y_{k}=0$, which in turn implies $(\mathrm{y}, \mathrm{y})$ is a Nash equilibrium of the bimatrix game $\left(\mathrm{C}^{\mathrm{T}} \mathrm{AC}, \mathrm{C}^{\mathrm{T}} \mathrm{A}^{\mathrm{T}} \mathrm{C}\right)$.

Conversely, let $(y, y)$ be a Nash equilibrium of the bimatrix game $\left(C^{\mathrm{T}} A C, C^{\mathrm{T}} A^{\mathrm{T}} C\right)$. Then, $y_{j}>0$ implies $e_{j}^{T} A y=\max _{i} e_{i}^{T}\left(C^{T} A C\right) y$. Let $T=\left\{j \in I^{n+1} \mid e_{j}^{T} C^{T} A C y=\right.$ $\left.\max _{\mathrm{i}} \mathrm{e}_{\mathrm{i}}^{\mathrm{T}}\left(\mathrm{C}^{\mathrm{T}} \mathrm{AC}\right) \mathrm{y}\right\}$, then $\mathrm{y}^{\mathrm{T}}\left(\mathrm{C}^{\mathrm{T}} \mathrm{AC}\right) \mathrm{y}=\Sigma_{\mathrm{j}} \mathrm{y}_{\mathrm{j}} \mathrm{e}_{\mathrm{j}}^{\mathrm{T}} \mathrm{A} \mathrm{y}=\Sigma_{\mathrm{j} \in \mathrm{T}} \mathrm{y}_{\mathrm{j}}\left(\max _{\mathrm{i}} \mathrm{e}_{\mathrm{i}}^{\mathrm{T}}\left(\mathrm{C}^{\mathrm{T}} \mathrm{AC}\right) \mathrm{y}\right)=$ $\max _{\mathrm{i}} \mathrm{e}_{\mathrm{i}}^{\mathrm{T}}\left(\mathrm{C}^{\mathrm{T}} \mathrm{AC}\right) \mathrm{y}$. This immediately implies $\mathrm{f}(\mathrm{y}) \leq \mathbf{0}$.

Proof 2.7 Let $\left(\mathrm{s}^{\mathrm{k}}, \mathrm{s}^{\mathrm{k}}\right)$ be a Nash equilibrium in $\left(\mathrm{A}, \mathrm{A}^{\mathrm{T}}\right)$, then $\left(\mathrm{e}_{\mathrm{i}}\right)^{\mathrm{T}}\left(\mathrm{C}^{\mathrm{T}} \mathrm{AC}\right) \mathrm{e}_{\mathrm{k}}=\left(\mathrm{s}^{\mathrm{i}}\right)^{\mathrm{T}} \mathrm{A} \mathrm{s}^{\mathrm{k}} \leq$ $s^{k} A s^{k}=\left(e_{k}\right)^{T}\left(C^{T} A C\right) e_{k}$ for all $i \in I^{n+1}$. Hence, by symmetry $\left(e_{k}, e_{k}\right)$ is a Nash equilibrium of $\left(C^{\mathrm{T}} \mathrm{AC}, \mathrm{C}^{\mathrm{T}} \mathrm{A}^{\mathrm{T}} \mathrm{C}\right)$.

Let $\left(\mathrm{s}^{\mathrm{k}}, \mathrm{s}^{\mathrm{k}}\right)$ be an evolutionary stable strategy in $\left(\mathrm{A}, \mathrm{A}^{\mathrm{T}}\right)$, we will show that a neighborhood $U \subset S^{n}$ exists such that $\left(e_{k}\right)^{T}\left(C^{T} A C\right) x>x^{T}\left(C^{T} A C\right) x$ for all $x \in U \backslash\left\{e_{k}\right\}$. Let $x=(1-\lambda) e_{k}+\lambda\left(\sum_{j \neq k} \mu_{j} e_{j}\right)$ with $\lambda \neq 0$, and let $s=\sum_{j \neq k} \mu_{j} s^{j}$. Then,

$\left(\mathrm{e}_{\mathrm{k}}\right)^{\mathrm{T}}\left(\mathrm{C}^{\mathrm{T}} \mathrm{AC}\right) \mathrm{x}=(1-\lambda)\left(\mathrm{s}^{\mathrm{k}}\right)^{\mathrm{T}} \mathrm{A} \mathrm{s}^{\mathrm{k}}+\lambda\left(\mathrm{s}^{\mathrm{k}}\right)^{\mathrm{T}} \mathrm{As}$, and $\mathrm{x}^{\mathrm{T}}\left(\mathrm{C}^{\mathrm{T}} \mathrm{AC}\right) \mathrm{x}=$

$(1-\lambda)^{2}\left(s^{\mathrm{k}}\right)^{\mathrm{T}} \mathrm{A} \mathrm{s}^{\mathrm{k}}+(1-\lambda) \lambda \mathrm{s}^{\mathrm{T}} \mathrm{A} \mathrm{s}^{\mathrm{k}}+(1-\lambda) \lambda\left(\mathrm{s}^{\mathrm{k}}\right)^{\mathrm{T}} \mathrm{As}+\lambda^{2} \mathrm{~s}^{\mathrm{T}} \mathrm{A}$ s. Hence,

$\left.\left.\left(\mathrm{e}_{\mathrm{k}}\right)^{\mathrm{T}}\left(\mathrm{C}^{\mathrm{T}} \mathrm{AC}\right) \mathrm{x}-\mathrm{x}^{\mathrm{T}}\left(\mathrm{C}^{\mathrm{T}} \mathrm{AC}\right) \mathrm{x}=\lambda\left((1-\lambda)\left(\left(\mathrm{s}^{\mathrm{k}}\right)^{\mathrm{T}} \mathrm{A} \mathrm{s}^{\mathrm{k}}-\mathrm{s}^{\mathrm{T}} \mathrm{A} \mathrm{s}^{\mathrm{k}}\right)\right)+\lambda\left(\left(\mathrm{s}^{\mathrm{k}}\right)^{\mathrm{T}} \mathrm{A} \mathrm{s}-\mathrm{s}^{\mathrm{T}} \mathrm{A} \mathrm{s}\right)\right)\right)$.

Next, we use that $\left(\mathrm{s}^{\mathrm{k}}, \mathrm{s}^{\mathrm{k}}\right)$ is an evolutionary stable strategy.

If $\left(\mathrm{s}^{\mathrm{k}}\right)^{\mathrm{T}} \mathrm{A} \mathrm{s}^{\mathrm{k}}>\mathrm{s}^{\mathrm{T}} \mathrm{A} \mathrm{s}^{\mathrm{k}}$ for all $\mathrm{s} \in \mathrm{S}^{\mathrm{m}}$, then taking $\lambda$ sufficiently close to zero yields $(1-\lambda)\left(\left(s^{k}\right)^{\mathrm{T}} A s^{k}-s^{T} A s^{k}\right)+\lambda\left(\left(s^{k}\right)^{T} A s-s^{T} A s\right)>0$.

If $\left(s^{k}\right)^{\mathrm{T}} A s^{k}=s^{T} A s^{k}$ for some $s \in S^{m}$, then $\left.\left(s^{k}\right)^{T} A s-s^{T} A s\right)>0$ since $s^{k} \neq$ $\sum_{j \neq k} \mu_{j} s^{j}$, hence $(1-\lambda)\left(\left(s^{k}\right)^{T} A s^{k}-s^{T} A s^{k}\right)+\lambda\left(\left(s^{k}\right)^{T} A s-s^{T} A s\right)=$ $\lambda\left(\left(\mathrm{s}^{\mathrm{k}}\right)^{\mathrm{T}} \mathrm{A} \mathrm{s}-\mathrm{s}^{\mathrm{T}} \mathrm{A} \mathrm{s}\right)>0$.

Therefore, $\left(e_{k}, e_{k}\right)$ is an evolutionary stable strategy in $\left(C^{T} A C, C^{T} A^{T} C\right)$.

The 'not conversely' statements in the proposition follow from this example.

Let $\mathrm{A}=\quad\left[\begin{array}{ll}0 & 1 \\ 1 & 0\end{array}\right]$, and let $\mathrm{s}^{1}=(1 / 3,2 / 3)^{\mathrm{T}}, \mathrm{s}^{2}=(1 / 6,5 / 6)^{\mathrm{T}}$, then

$\mathrm{C}^{\mathrm{T}} \mathrm{A} \mathrm{C}=\left[\begin{array}{cc}10 / 18 & 7 / 18 \\ 7 / 18 & 5 / 18\end{array}\right]$.

It follows easily that $\left(e_{1}, e_{1}\right)$ is an evolutionary stable strategy in $\left(C^{\mathrm{T}} A C, C^{\mathrm{T}} \mathrm{A}^{\mathrm{T}} \mathrm{C}\right)$, but $\left(\mathrm{s}^{1}, \mathrm{~s}^{1}\right)$ is not a Nash equilibrium in $\left(\mathrm{A}, \mathrm{A}^{\mathrm{T}}\right)$.

Proof 2.8 Let y be a saturated equilibrium, and let $U \subseteq S^{\mathrm{n}}$ be a neighborhood of $y$, such that $H_{y}(x)>0$ for all $x \in U \backslash\{y\}$. Then $H_{y}(x)=(y-x)^{T}(G(x)-f(x))>0$, therefore $(y-x)^{T} G(x)>(y-x)^{T} f(x)=y^{T} f(x)$. Hence, (5) implies (3). Reverting all inequalities, yields the converse implication.

Proof 3.1 Let $\mathrm{K} \subseteq \mathrm{I}^{\mathrm{n}+1}$, satisfing $\mathrm{f}_{\mathrm{k}}(\mathrm{x})>0$, whenever $\mathrm{x}_{\mathrm{k}}=0$ for all $\mathrm{k} \in \mathrm{K}$.

Let $S(K)=\left\{x \in S^{n} \mid x_{k}=0\right.$, for some $\left.k \in K\right\}$. Since $f$ is continuous, there exists $\delta_{\mathrm{k}}>0$ for each $\mathrm{k} \in \mathrm{K}$, such that $\mathrm{x}_{\mathrm{k}}<\delta_{\mathrm{k}}$ implies $\mathrm{f}_{\mathrm{k}}(\mathrm{x})>0$. Now, take $0<\delta<\min \left\{\delta_{\mathrm{k}} \mid \mathrm{k} \in \mathrm{K}\right\}, \mathrm{U}=\left\{\mathrm{u} \in \mathrm{S}^{\mathrm{n}} \mid \mathrm{u}_{\mathrm{k}} \leq \delta\right.$ for all $\left.\mathrm{k} \in \mathrm{K}\right\}$, and let $\mathrm{V}: \mathrm{U} \rightarrow \mathbb{R}^{\mathrm{n}+1}$ be given by $\mathrm{V}(\mathrm{x})=\min _{\mathrm{k} \in \mathrm{K}} \mathrm{x}_{\mathrm{k}}$ for all $\mathrm{x} \in \mathrm{U}$. Clearly, $\mathrm{V}(\mathrm{x})=0$ for all $\mathrm{x} \in \mathrm{S}(\mathrm{K})$, $\mathrm{V}(\mathrm{x})>0$ for all $\mathrm{x} \in \mathrm{U} \mathrm{US}(\mathrm{K})$. Furthermore $\mathrm{dV}(\mathrm{x}) / \mathrm{dt}=\Sigma_{\mathrm{j}} \partial \mathrm{V}(\mathrm{x}) / \partial \mathrm{x}_{\mathrm{j}} d \mathrm{dx}_{\mathrm{j}} / \mathrm{dt}=\mathrm{G}_{\mathrm{i}^{*}}(\mathrm{x})$, where $i^{*} \in K$ is some index satisfying $x_{i^{*}}=\min _{k \in K} x_{k}$. Therefore, if $x \in S(K)$, then $\mathrm{G}_{\mathrm{i}^{*}}(\mathrm{x})=0$, and if $\mathrm{x} \in \mathrm{U} \backslash \mathrm{S}(\mathrm{K})$, then $\mathrm{G}_{\mathrm{i}^{*}}(\mathrm{x})>0$.

Hence $\mathrm{dV}(\mathrm{x}) / \mathrm{dt}=0$ for all $\mathrm{x} \in \mathrm{S}(\mathrm{K})$, whereas $\mathrm{dV}(\mathrm{x}) / \mathrm{dt}>0$ for all $\mathrm{x} \in \mathrm{U} \backslash \mathrm{S}(\mathrm{K})$, implying that $\mathrm{V}$ is a strict Lyapunov-function on $\mathrm{U}$. For each trajectory $\{\mathrm{z}(\mathrm{t})\}_{\mathrm{t} \geq 0}$ with $\mathrm{z}(0) \in \mathrm{U} \backslash \mathrm{S}(\mathrm{K}),\{\mathrm{V}(\mathrm{z}(\mathrm{t}))\}_{\mathrm{t} \geq 0}$ increases strictly while $\{\mathrm{z}(\mathrm{t})\}_{\mathrm{t} \geq 0} \subset \mathrm{U} \backslash \mathrm{S}(\mathrm{K})$. Therefore, 
$t^{*} \geq 0$ exists, satisfying $\mathrm{V}\left(\mathrm{z}\left(\mathrm{t}^{*}\right)\right)=\delta$, hence the trajectory leaves $\mathrm{U}$.

Proof 3.2 Let $\mathrm{f}$ be a relative fitness function, differentiable at all $\mathrm{x} \in \mathrm{S}^{\mathrm{n}}$. Let $\partial \mathrm{f}_{\mathrm{i}}(\mathrm{x}) / \partial \mathrm{x}_{\mathrm{k}}>0$ for all $\mathrm{k} \neq \mathrm{i}, \mathrm{x}>\boldsymbol{0}$. Let $\mathrm{y} \in \mathrm{S}^{\mathrm{n}}$ satisfy $\mathrm{y}>\boldsymbol{0}$ and $\mathrm{f}(\mathrm{y})=\mathbf{0}$.

Define $F: \mathbb{R}^{n+1}{ }_{+} \rightarrow \mathbb{R}^{n+1}$, for every $p \in \mathbb{R}^{n+1}$ by $F(p)=f(x(p))$, where $x(p) \equiv p /\|p\|_{1}$. For $\mathrm{p} \in \mathbb{R}^{\mathrm{n}+1}, \mathrm{p}>\mathbf{0}, \mathrm{F}$ is continuous, $\mathrm{p}^{\mathrm{T}} \mathrm{F}(\mathrm{p})=\left(\|\mathrm{p}\|_{1}\right) \mathrm{x}(\mathrm{p})^{\mathrm{T}} \mathrm{f}(\mathrm{x}(\mathrm{p}))=0$, and $\mathrm{F}$ is positively homogeneous of degree zero. $\mathrm{F}$ is differentiable, moreover $\partial \mathrm{F}_{\mathrm{i}}(\mathrm{p}) / \partial \mathrm{p}_{\mathrm{k}}=$ $\left(\|\mathrm{p}\|_{1}\right)^{-1} \partial \mathrm{f}_{\mathrm{i}}(\mathrm{x}(\mathrm{p})) / \partial \mathrm{x}_{\mathrm{k}}(\mathrm{p})>0$. By Lemma 3.1, it follows that

(a) there exists $q \in \mathbb{R}^{n+1}, q>\mathbf{0}$, satisfying $F(q)=\mathbf{0}$, and

(b) if $F(p)=\mathbf{0}$ for some $\mathrm{p}>\mathbf{0}$, then $\mathrm{p}=\lambda \mathrm{q}$ for some $\lambda>0$.

Let $\mathrm{q}>\mathbf{0}$ and $\mathrm{F}(\mathrm{q})=\mathbf{0}$. Then $\mathrm{x}(\mathrm{q}) \in \mathrm{S}^{\mathrm{n}}$, and $\mathrm{F}(\mathrm{q})=\mathrm{F}(\mathrm{x}(\mathrm{q}))=0$. Then $\mathrm{x}(\mathrm{q})=\mathrm{y}$.

\section{REFERENCES}

Alchian, A., 1950, Uncertainty, evolution and economic theory, Journal of Political Economy 58, 211-221.

Arrow, K.J., H.D. Block and L. Hurwicz, 1959, On the stability of the competitive equilibrium II, Econometrica 27, 82-109.

Axelrod, R., 1984, "The Evolution of Cooperation", Basic Books, NY.

Axelrod, R., and W.D. Hamilton, 1981, The evolution of cooperation, Science 211, 1390-1396.

Bomze, E., and E.E.C. Van Damme, 1992, A dynamical characterization of evolutionary stable states, Annals of Operations Research 37, 229-244.

Boylan, R.T., 1992, Laws of large numbers for dynamical systems with randomly matched individuals, Journal of Economic Theory 57, 473-504.

Debreu, G., 1970, Economies with a finite set of equilibria, Econometrica 38, 387-392.

Debreu, G., 1974, Excess demand functions, Journal of Mathematical Economics 1, 15-23.

Dierker, E., 1972, Two remarks on the number of equilibria of an economy, Econometrica 40, 951-953.

Dosi, G., C. Freeman, R. Nelson, G. Silverberg, and L. Soete, 1988, "Technical Change and Economic Theory", Pinter, London.

Doup, T.M., G. van der Laan and A.J.J. Talman, 1987, The $\left(2^{\mathrm{n}+1}-2\right)$-ray algorithm: a new simplicial algorithm to compute economic equilibria, Mathematical Programming 39, 241-252.

Doup, T.M., 1988, "Simplicial Algorithms on the Simplotope", Springer, Berlin.

Dow, G.K., 1986, Stability analysis for profit-responsive selection mechanisms, Mathematical Social Sciences 12, 169-183.

Eaves, B.C., 1972, Homotopies for computation of fixed points, Mathematical Programming 3, 1-22.

Friedman, D., 1991, Evolutionary games in economics, Econometrica 59, 637-666.

Friedman, M., 1953, The methodology of positive economics, in: "Essays in positive economics", University of Chicago Press, IL.

Gilboa, I., and A. Matsui, 1992, A model of random matching, Journal of Mathematical Economics 21, 185-187.

Hannan, M.T. and J. Freeman, 1989, "Organizational ecology", Harvard University Press, Cambridge, MA.

Hansen, R.G., and W.F. Samuelson, 1988, Evolution in economic games, Journal of Economic Behavior and Organization 10, 315-338.

Harker, P.T., and J.S. Pang, 1990, Finite-dimensional variational inequality and nonlinear complementarity problems: A survey of theory, algorithms and applications, Mathematical Programming 48, 161-220.

Hirsch, M.W., and S. Smale, 1974, "Differential Equations, Dynamical Systems and Linear Algebra", Academic Press, NY.

Hofbauer, J., and K. Sigmund, 1988, "The Theory of Evolution and Dynamical Systems", Cambridge University Press, Cambridge.

Kakutani, S., 1941, A generalization of Brouwer's fixed-point theorem, Duke Mathematical Journal 8, 457-459.

Keenan, D., 1981, Further remarks on the Global Newton method, Journal of Mathematical Economics 8, 159165.

Kuhn, H.W., 1968, Simplicial approximation of fixed points, Proceedings of the National Academy of Sciences USA 61, 288-328.

Kuhn, H.W., 1969, Approximate search for fixed points, Computation Methods in Optimization Problems 2 , 
199-211.

Laan, G. van der, and A.J.J. Talman, 1979, A restart algorithm for computing fixed points without an extra dimension, Mathematical Programming 17, 74-84.

Laan, G. van der, and A.J.J. Talman, 1987, Computing economic equilibria by variable dimension algorithms: state of the art, FEW 270, Tilburg University.

Laan, G. van der, and A.J.J. Talman, L. Van der Heyden, 1987, Simplicial variable dimension algorithms for solving the nonlinear complementarity problem on a product space of unit simplices using a general labelling, Mathematics of Operations Research 12, 377-397.

Mailath, G.J., 1992, Introduction: Symposium on evolutionary game theory, Journal of Economic Theory 57, 259-277.

Mantel, R., 1974, On the characterization of aggregate excess demand, Journal of Economic Theory 7, 348-353.

Maynard Smith, J., and G.A. Price, 1973, The logic of animal conflict, Nature 246, 15-18.

Metcalfe, J.S., 1994, Competition, Fisher's principle and increasing returns in the selection process, Journal of Evolutionary Economics 4, 327-346.

Meyerson, R.B., G.B. Pollock, and J. Swinkels, Viscous population equilibria, Games and Economic Behavior 3, 101-109.

Nachbar, J.H., 1990, 'Evolutionary' selection dynamics in games: Convergence and limit properties, International Journal of Game Theory 19, 59-89.

Nachbar, J.H., 1991, A comment on 'evolution in economic games', Journal of Economic Behavior and Organization 16, 355-360.

Nash, J., 1951, Non-cooperative games. Annals of Mathematics 54, 286-295.

Nelson, R., and S.G. Winter, 1982, "An Evolutionary Theory of Economic Change", Harvard University Press, Cambridge, MA.

Nowak, M., and K. Sigmund, 1993, Chaos and the evolution of cooperation, Proceedings of the National Academy of Sciences USA 90, 5091-5094.

Saari, D.G., 1985, Iterative price mechanisms, Econometrica 53, 1117-1131.

Saari, D.G., and C. Simon, 1978, Effective price mechanisms, Econometrica 46, 1097-1125.

Samuelson, P., 1947, "Foundations of Economic Analysis", Harvard University Press, Cambridge, MA.

Scarf, H., 1960, Some examples of global instability of competitive equilibrium, International Economic Review 1, 157-172.

Scarf, H. (with the collaboration of T. Hansen), 1973, "The Computation of Economic Equilibria," Yale University Press, New Haven, CT.

Smale, S., 1976, A convergent process of price adjustment and Global Newton methods, Journal of Mathematical Economics 3, 107-120.

Sonnenschein, H., 1972, Market excess demand functions, Econometrica 40, 549-563.

Sonnenschein, H., 1973, Do Walras' identity and continuity characterize community excess demand functions?, Journal of Economic Theory 6, 345-354.

Taylor, P.D., and L.B. Jonker, 1978, Evolutionary stable strategies and game dynamics, Mathematical Biosciences 40, 145-156.

Todd, M.J., 1976, "The Computation of Fixed Points and Applications", Springer, Berlin.

Uzawa, H., 1961, The stability of dynamic processes, Econometrica 29, 617-631.

Van Damme, E.E.C., 1991, "Stability and Perfection of Nash Equilibria", Springer, Berlin.

Varian, H.R., 1978, "Microeconomic analysis", W.W. Norton \& Company, NY.

Weissing, F.J., 1990, Evolutionary stability and dynamic stability in a class of evolutionary normal form games, in "Game Equilibrium Models I, Evolution and Game Dynamics (R. Selten, Ed.), Springer, Berlin.

Winter, S.G., 1964, Economic 'natural' selection and the theory of the firm, Yale Economic Essays 4, $225-272$.

Winter, S.G., 1975, Optimization and evolution in the theory of the firm, in "Adaptive Economic Models" (R.H. Day and T. Grovers, eds.), NY.

Zeeman, E.C., 1981, Dynamics of the evolution of animal conflicts, Journal of Theoretical Biology 89, 249-270. 